\title{
LA CARTILLA BILINGÜE CHILCATUN. CHILE DUGNU (1899). \\ TEXTO ORIGINALY CONSIDERACIONES EN TORNO A LA ALFABETIZACIÓN MAPUCHE ${ }^{1}$
}

\author{
José Miguel Ortiz \\ Universidad de Chile \\ Santiago, Chile \\ kmortizb@gmail.com \\ Gertrudis Payàs \\ Universidad Católica de Chile \\ Temuco, Chile \\ gpayas@uct.cl
}

En estos últimos años hemos presenciado un creciente interés por la historia de la educación en la Araucanía (Donoso, Flores y Azócar, Mansilla et al.), así como un retorno a los textos de la araucanística clásica en busca de claves para comprender los debates en torno a la relación entre los mapuche y la república, las representaciones que sobre estos se construyeron y difundieron por medio del sistema escolar y también las descripciones científicas en el tránsito del

\footnotetext{
Este trabajo se enmarca en el proyecto Fondecyt Regular 1170419: Mediación lingüistico-cultural y castellanización en los ámbitos de contacto mapudungun-castellano derivados del proceso de chilenización de la Araucanía (1880-1930). Respecto al documento que presentamos, agradecemos, en primer lugar, a Marisa Malvestitti y María Andrea Nicoletti por habérnoslo dado a conocer y habernos proporcionado la copia fotográfica que presentamos; asimismo, agradecemos al Archivo del Museo Bartolomé Mitre, de Buenos Aires, la autorización para publicarla. En cuanto a la investigación, vaya nuestro agradecimiento especial a la Hna. Jacqueline Juárez y la Sra. Loreto Fernández, del Archivo de la Provincia Bernarda Morin de las Hermanas de la Providencia, quienes generosamente nos proporcionaron fuentes adicionales y respondieron a nuestras consultas.
} 
siglo XIX al XX (Mora y Samaniego). Este interés ha favorecido la difusión de documentos y ha supuesto una revisión y actualización de las historiografías y antropologías de Chile, Argentina y Wallmapu (Vezub y De Jong). En particular, el debate sobre el lugar y el devenir de la escritura alfabética en el mundo mapuche (Pavez) ha cuestionado el supuesto culturalista de su esencia oral y, por tanto, ahistórica (Menard, “¿Qué fue primero”). Paralelamente y, a veces, de manera complementaria, los estudios de historiografía lingüística (Nicoletti y Malvestitti, "Catecismos" y "Werkenealu”; Malvestitti, "Lingüística misionera" y "Dios ñizugu"; Malvestitti y Nicoletti, "Evangelización") han coincidido con este giro escritural y han venido a acrecentar el archivo asociado a la cultura mapuche y a enriquecer sus interpretaciones. En historia de la educación, sin embargo, los avances se han dado principalmente en el conocimiento de los proyectos educacionales, redes e infraestructuras, así como estadísticas escolares y prácticas de aculturación, haciendo en general una justificada crítica del asimilacionismo y el racismo prevalecientes.

Aunque son conocidas las políticas de castellanización por la vía escolar en el periodo de radicación (1894-1930) (Durán y Ramos), sigue siendo opaco el proceso mismo llevado a cabo en las aulas y los recursos pedagógicos empleados; tampoco se ha estudiado sistemáticamente cómo se codificaron en la lengua escrita las representaciones ideológicas de las lenguas implicadas ni la relación que se pueda establecer con el desplazamiento del mapuzugun del espacio público y su relegación a los espacios intraétnicos (Payàs et al.). La escasez de registros que permitan comprender a cabalidad este proceso hace precisamente notable el hallazgo que aquí presentamos. Se trata de una cartilla de enseñanza de la lectoescritura bilingüe, mapuzugun-castellano, sin nombre de autor, titulada Chilcatun. Chile Dugnu, publicada en 1899 por la congregación católica de las Hermanas de la Providencia de Santiago. Los pocos registros que hay de su existencia la vinculan con otra publicación, también anónima: el Manual de Piedad en castellano y en mapuche (araucano) para texto de lectura de los indígenas de Chile, salida el mismo año de la misma imprenta. Hemos podido confirmar esta vinculación en el hecho de que comparten un sistema de escritura que no se encuentra en otras publicaciones del periodo.

Acompañando la reproducción fotográfica de la cartilla Chilcatun presentamos a continuación un análisis de sus condiciones de producción. Situamos la cartilla en su contexto histórico y exponemos hallazgos y lagunas sobre su origen y autoría; luego, describimos y analizamos sus características macrotextuales, textuales e iconográficas, con especial atención 
a la representación ortográfica y a las relaciones intertextuales; y, por último, planteamos conclusiones acerca de su posible lugar en el archivo mapuche y en los discursos sobre la lengua y los debates sobre la enseñanza de la lectura y la escritura en el periodo.

En el proceso de modernización de la enseñanza y de ampliación de la primaria pública que caracteriza este periodo va a operar un circuito oficial de circulación de textos que, en el sur, y debido a la situación de colonialismo republicano que vive el pueblo mapuche, tendrá algunos rasgos particulares, entre ellos la presencia de las misiones. Hasta ahora, no se ha prestado una atención particular a las posibles redes de cooperación que pueden haberse establecido entre las congregaciones que se encargaron de la educación de los niños mapuche, así como sus relaciones con estudiosos del pueblo mapuche, en lo relativo a la enseñanza del castellano y el rol del mapuzugun en la educación. Al rastrear el origen de esta cartilla hemos descubierto algunos hilos de esta red educativo-misional que nos llevan a poner de relieve la labor de las Hermanas de la Providencia, congregación de origen canadiense, de carácter no misionero, que parece haber tenido una labor destacada en la historia de la educación mapuche. Las elecciones que se tomaron en el diseño del Chilcatun y su configuración textual dan cuenta precisamente de esta red de prácticas y discursos en los que se inscribe.

\section{LA ENSEÑANZA DE LA LECTURA Y LA ESCRITURA EN EL CAMBIO DE SIGLO}

La segunda mitad del siglo XIX y las primeras décadas del XX en Chile estuvieron marcadas por transformaciones sociales y políticas que suelen entenderse como parte del proceso de chilenización del territorio y de modernización del Estado. Este proceso trajo consigo una reorganización política que definía el rumbo de lo social, la educación, la religión y, desde luego, el régimen de los territorios recientemente anexados como resultado de las campañas militares tanto en el norte como en el sur. La instauración de la primaria pública y la ampliación progresiva de su cobertura durante este periodo suponen la primera red territorial de institucionalización del Estado nacional (Serrano et al., Historia I) y un circuito oficial de circulación de textos.

De esta manera, "la educación y la lectura estaban literalmente irrumpiendo en los hogares chilenos" (Poblete 32). Una de las formas de esta irrupción son los textos de estudio, que para una gran cantidad de niños y niñas de la 
segunda mitad del siglo XIX fueron la primera aproximación al impreso. Estos libros, los primeros textos de circulación masiva, "fueron también el primer impreso que ingresó a la vida doméstica de las familias populares" (Serrano et al., Historia I 278). Un análisis de estos a partir del número de ejemplares impresos según asignatura entre el año 1854 y 1878 revela que "tan relevantes como los tres básicos -el silabario, el catecismo y la aritméticafueron los 'textos de lectura' de carácter religioso moral que servían de apoyo" (Serrano et al., Historia I 272). En un periodo posterior, entre 1886 y 1909, la concentración parece haber sido mayor entre los silabarios y libros de lectura, mientras que los textos destinados a las demás asignaturas fueron reduciendo su presencia proporcional, quedando hacia el Centenario solo los de catecismo y religión por sobre el 10\% del total de la muestra (Serrano et al., Historia II 181). Esto es indicativo del papel que seguía teniendo la religión en la educación nacional, pese al proceso de modernización y secularización del Estado. La Ley de Instrucción Primaria de 1860, de hecho, estableció que debía enseñarse, al menos, lectura, escritura, elementos de aritmética práctica, el catecismo y el sistema legal de pesos y medidas (Serrano et al., Historia I 293), por lo que la religión tuvo una presencia constante en el currículum escolar, al menos hasta la reforma de 1920. Si en los textos de estudio dentro del contexto chileno general había una preponderancia de la religión, en el caso del territorio mapuche y las escuelas misionales fue aún mayor.

La ampliación de la cobertura escolar tuvo sus características particulares en el territorio mapuche, ahora anexado al territorio nacional. El Estado, carente de una política educativa específica para la población mapuche, delegó en la Iglesia católica la educación primaria, subvencionando escuelas misionales, con lo que se dio un alto grado de continuidad con la tradición educacional colonial. Se podría decir, de hecho, que la "ausencia" del Estado docente, o la delegación del papel educador, favoreció la permanencia de un modelo de lectura reducido a textos religiosos y fuertemente tutelado por los misioneros, en tanto mediadores profesionales e intérpretes autorizados. Sus figuras corresponden a lo que Anne-Marie Chartier llama el "maestro catequístico" (25-28), agentes de un modelo cuyo objetivo era el aprendizaje de la doctrina y para quienes la lectura, más que un fin, constituía un medio. No obstante esta caracterización de las formas que adquirió la educación indígena, como veremos en la composición del Chilcatun, algunos elementos de laicismo y nacionalismo obligan a cuestionar el supuesto exclusivamente católico del afán educador. 
En la época en que se publica la cartilla, la enseñanza de la lectoescritura en el sistema educativo era fuertemente debatida. Ese debate se daba, desde luego, sobre la enseñanza del castellano y no alcanzaba el mapuzugun, que era también lengua que se usaba en las escuelas, aunque solo en la Araucanía y en las escuelas misionales. Al delegar la educación mapuche en la Iglesia, no hubo discusiones públicas sobre cuál sería la lengua de enseñanza, como en otros contextos de colonialismo, dado que, por entonces, la supremacía política del español sobre las lenguas indígenas en Chile se daba por sentada (Rojas). Aun entre los misioneros, y considerando su afecto por las lenguas indígenas derivado de la labor evangelizadora, en el siglo XIX era de sentido común que el mapuzugun sería utilizado como lengua de instrucción solo hasta que los estudiantes aprendieran castellano (Durán y Ramos), esto es, como un paso en la transición hacia la lengua dominante. El hallazgo de un instrumento de enseñanza de la lectoescritura sobre la base del mapuzugun en el horizonte de la castellanización ofrece la posibilidad de comprender de mejor manera este proceso.

Desde el periodo colonial, los instrumentos de enseñanza más difundidos fueron el "catón" (por el nombre del autor latino de un manual de instrucción muy popular en la Edad Media europea) y la cartilla de alfabetización, y esta lo siguió siendo hasta el inicio de la vida republicana. La cartilla era un arte breve para aprender a leer y escribir, mientras que el catón contenía ejemplos de frases y pequeños textos para ejercitarse en la lectura (Demerson), muchas veces de carácter moral. Algunas cartillas, como la que nos ocupa, combinaban las dos funciones, y muchas gramáticas coloniales de lenguas indígenas contenían elementos de cartilla y catón. Respecto a su utilidad y eficacia, la cartilla, "si bien partía mostrando a los alumnos distintas combinaciones de vocales y consonantes, lo hacía en forma poco sistemática e incompleta, enseñando más que a leer, a memorizar textos escritos, especialmente textos de carácter religioso" (Serrano et al., Historia I 296). Para la alfabetización en castellano, al menos desde 1840, con la actuación destacada de Domingo Faustino Sarmiento en Chile, se da una proliferación de silabarios, un tipo de cartilla en el que la enseñanza de la lectura comenzaba con el aprendizaje del nombre de las letras y luego de las sílabas. En la década de 1880, y confirmado luego en el Congreso Pedagógico de 1889, se rechaza este modelo y se reconoce la necesidad de introducir el fonetismo y la enseñanza simultánea de lectura y escritura. Fundamental en este sentido es El Nuevo método (fonético, analítico-sintético) para la enseñanza simultánea de la lectura i escritura, publicado en 1884 y adoptado como texto oficial en 1894, 
de Claudio Matte. Este texto, profusamente distribuido en las escuelas, se diferencia de los métodos anteriores en varios aspectos:

en el silabario niñas y niños debían aprender los nombres de las letras, lo que en la práctica difería de su sonido. El nuevo método, en cambio, proponía solo la enseñanza del sonido de las letras $(\mathrm{m})$ y no su nombre (eme). De ahí derivaba que el método se denominara fonético. En segundo lugar, los sonidos de las letras no se enseñarían de manera aislada, sino relacionadas con palabras de fácil comprensión, "por eso se toman [...] vocablos que representan cosas familiares a los niños i, en lo posible, capaces de excitar su curiosidad" (Matte IV). Igualmente, para despertar el interés de la infancia, se proponía la utilización de imágenes relacionadas también con la lección de objetos. Una vez fijada la idea del objeto representada por la palabra, el profesor la descomponía en sílabas (Araya 54).

En este escenario, se dio una coexistencia de dos métodos de enseñanza: antiguo y moderno. En el primero, los estudiantes repetían las letras con un silabario o con un cuadro de lectura en sus manos, imitando de memoria los sonidos de las letras. En el segundo, ya no se buscaba enseñar los sonidos de las letras, sino su escritura (Araya 78). Nuestro Chilcatun se inserta en este contexto de debates pedagógicos y responde al modelo moderno.

\section{DUDAS Y CERTEZAS SOBRE SU ORIGEN Y AUTORÍA}

Si bien cartillas y catones fueron instrumentos pedagógicos ampliamente difundidos en el mundo hispanoamericano para la enseñanza de la lectura y la escritura en castellano desde el periodo colonial temprano (Torre Revello) -incorporadas a veces en las gramáticas de las lenguas indígenas-, las cartillas bilingües se popularizan solo entrado el siglo $\mathrm{XX}$, con las campañas de alfabetización indígena gubernamentales (Vivar). Por su carácter institucional, estas cartillas solían ser anónimas, aunque es evidente que se confeccionaban en colaboración con los hablantes de las lenguas en cuestión.

En este caso, partimos sin saber quién o quiénes, mapuches y no mapuches, participaron en la elaboración de la cartilla, y con unos pocos datos que se dan en el propio documento, que nos permiten suponer que fue concebida en la institución de la Divina Providencia, congregación femenina no dedicada 
específicamente a las misiones, aunque, como se verá, con vínculos misionales. La cartilla obedece también a intereses civiles, pues fue supervisada, como tantas otras obras relativas al mapuzugun, por el filólogo y pedagogo Rodolfo Lenz y, además, costeada por el gobierno. Solo dos años antes, Lenz había publicado el último de sus Estudios Araucanos y su autoridad como experto araucanista estaba ya asentada, proyectando su papel como un "vector glotopolítico" fundamental del periodo (Ennis y Rojas). No podemos saber por ahora si intervino como redactor de la cartilla o si, como se indica, solo la revisó. Lo que nos dice el texto, en particular la licencia de impresión de la autoridad diocesana ${ }^{2}$, es que la impresión y publicación la "desean hacer las Hermanas de la Providencia", en cuya Imprenta San José, en Santiago, efectivamente, se elabora.

El hecho de tener imprenta le significó a la congregación de la Divina Providencia ser un polo de atracción para la intelectualidad católica. Ahí se publicó durante varios años la Revista Católica, órgano oficial de la Iglesia, de manera que cabe imaginar que en la congregación de la Providencia no solo hayan circulado libros, sino que se hayan tejido redes de cooperación entre el clero secular y regular y los intelectuales laicos afines.

La congregación de las Hermanas de la Providencia, de origen francocanadiense, llegó a Chile en 1853. El entonces presidente Manuel Montt les ofrece hacerse cargo de una casa de asilo de huérfanos en Santiago que es, finalmente, donde se establecieron; construyeron una iglesia, les fue donado el Asilo del Salvador y expandieron desde ahí sus áreas de influencia. Así, instalaron la casa del noviciado, el orfanato y escuelas por todo el país: Valparaíso en 1858, Concepción en 1867, La Serena en 1872, Linares en 1894, Vicuña en 1904, Ovalle en 1906, y otras. En 1894 llegaron a Temuco, donde rápidamente, y aun sin saber su lengua, buscaron atraer a la población mapuche con el fin de catequizarla y "merecer su confianza": "mientras no supieron el idioma, se les hablaba por intérprete" (Hermanas de la Providencia

2 No está de más señalar que quien firma la licencia es Manuel Antonio Román, secretario del Arzobispado, miembro de la Academia Chilena de la Lengua desde 1915 y director de la Revista Católica desde 1901, donde redacta una sección denominada "Filología". Román fue un paladín del normativismo hispanista y su obra más destacada fue el Diccionario de chilenismos (1901-1918). Tanto esta obra como la revista se publicaron precisamente en la imprenta de las Hermanas de la Providencia. Desde el espacio de la revista polemiza precisamente con Rodolfo Lenz a partir de la publicación de su Diccionario Etimológico. Véase al respecto (Cáceres, Ortiz y Rojas). 
154). Ahí establecieron una escuela gratuita con internado para "las niñas del pueblo y se recibió a algunas niñas indígenas. Además, se abrió un pequeño colegio para la educación de las niñas de primera sociedad" (Hermanas de la Providencia 155). Si damos crédito a una fuente periodística de 1901, en esa fecha la escuela tenía 350 niñas mapuche, de las cuales 200 eran internas ${ }^{3}$. Poco se conoce sobre el trabajo de esta congregación con la población mapuche, aunque su labor parece haber sido significativa en el periodo, pues fueron invitadas a participar al Congreso Araucano que se realizó en 1916, propuesto por el arzobispo Juan Ignacio González "para despertar en el público chileno el interés por la obra nacional de la Misión” y que contó con la asistencia de "todas las órdenes que trabajaban en la Araucanía" (Noggler 137).

Sabemos que algunas hermanas de esta congregación tenían algún conocimiento del mapuzugun, ya que "para realizar esa enseñanza, algunas de las monjas han debido ellas mismas aprender el mapuche"". Por las fechas de las fuentes consultadas, este aprendizaje, curiosamente, parece haberse dado ya en Santiago, quizás en contacto con algunas niñas mapuche enviadas allá a estudiar, como fueron las hermanas Kallfüñamko, en 1870, de quienes hablaremos más adelante. No es de extrañar, entonces, que el capuchino bávaro Anselmo de Kamin (Carmín, en la fuente), que había llegado a Chile junto con Félix de Augusta en 1896 y que al año siguiente estaba en Boroa, con la misión de fundar escuela, al saber "que algunas de [las] Hermanas hablaban mapuche, é inmediatamente, deseoso de comenzar cuanto antes su santa misión, se dirigió á la Providencia á solicitar libros para aprender el idioma” (Lizana 59). ¿Serían estos libros, acaso, alguna de las ediciones de

\footnotetext{
Recorte de periódico no identificado, titulado "Araucania" y firmado V.E.L., de fecha 26 de octubre de 1901. Forma parte de la colección documental que alberga el archivo del convento de la Divina Providencia en Santiago. El artículo relata una visita al colegio de Temuco, donde las visitas son recibidas por la superiora, la Madre Mectilde Lizana. En la historia de la casa de la Providencia en Temuco (Lizana) se registran, además, algunos nombres: "Entre los muchos indios que venían a pedir instrucción religiosa, se distinguió María Nahuelpán, madre de Rosa y Juana Cayupil, las primeras indiecitas que llegaron a nuestra casa” (51), María Dolores Inaihual (63), Isabel Queupucara (65), Juana María Nahuelquín y su papá José Manuel (67), María Antonia Mulato (68), “Juan Marinao, padre de dos mapuchitas que fueron á Santiago con nuestras Hermanas, [...] una de ellas llamada Francisca” (62).

El relato que figura en la misma fuente periodística de 1901 (ver nota anterior) prosigue: "Nos tocó presenciar la clase de Catecismo que en ese momento hacía una de las Madres, que pertenece á una distinguida familia de Santiago, y no pudimos ocultar la admiración mezclada de risa que nos causó ver a una religiosa hablando la lengua de Caupolicán y Colocolo".
} 
la obra de Febrés, que circularon ampliamente en este periodo (Malvestitti y Payàs), o alguno de los últimos Estudios Araucanos de Lenz, que algunos misioneros utilizaban para aprender y estudiar la lengua (Menard y Pavez 174)? Es muy probable que desde el momento en que se propusieron aprender el mapuzugun existieran estos libros en la biblioteca del colegio de Temuco. Anselmo de Kamin acudía regularmente a la casa de esta congregación en Temuco a confesar y estableció con ella y su entonces directora, sor Mechtilde (o Mectilde) de la Santísima Trinidad Lizana, una intensa colaboración, como lo señala el P. Burcardo de Röttingen (81). Según se indica en la historia de la casa de Temuco, fue el P. Anselmo quien "escribió un Manual de oraciones é instrucción religiosa, en mapuche y castellano, para uso de los niños que se educan en la Providencia del Sagrado Corazón de Temuco. Esta obrita se imprimió en la Casa Central de la Providencia" (Lizana 61). Dada la relación entre este manual y el documento que presentamos, y la coincidencia de fechas, nos parece plausible que el P. Kamin haya estado también en el origen del Chilcatun, con la colaboración de algunas monjas mapuche-hablantes o incluso alumnas mapuche.

De las escuelas misionales y religiosas instaladas en territorio mapuche, Guevara destaca: "El mas importante por su magnífico edificio i los recursos de que dispone es, sin duda, el de la Providencia" (70), lo que en boca del que fue director del principal establecimiento laico de Temuco, el Liceo, implica un reconocimiento significativo. Esta escuela, al igual que todas las demás, y tal como se indica en la mayoría de los relatos misionales, tuvo dificultad al inicio para convencer a los padres mapuche de enviar a sus hijos, "pero cuando vieron que sus hijos sabían leer un libro, escribir cartas i que podían coserles una camisa, entonces se manifestaron mui contentos", según el testimonio de sor Mecthilde Lizana (71).

Como hemos dicho, es notable que hayan llegado niñas mapuche a educarse con las monjas de la Providencia en Santiago en 1870, antes de que se estableciera el colegio en Temuco. Varias fuentes y estudios registran el caso de dos hermanas de apellido Kallfüñamko que residieron entre 1870 y 1875 en la casa de Santiago, y lo vinculan a la historia de la educación femenina mapuche. Según Serrano, que toma el dato de la Memoria del Ministro de Justicia, Culto e Instrucción Pública presentada ante el Congreso Nacional de 1876:

El inicio de la educación femenina araucana tuvo la particularidad de iniciarse con dos profesoras mapuches, las hermanas Califuñanco 
[Kallfüñamko], de 18 y 20 años, que habían sido enviadas por los capuchinos a estudiar a Santiago, donde las religiosas de la Providencia. Las dos primeras escuelas se instalaron en 1875 en las misiones de Queule e Imperial (444).

De su existencia y formación en Santiago, aunque sin dar fecha, nos habla también la crónica franciscana de Pamplona (262-263), que afirma que las hermanas Kallfünamko eran originarias de Queule, donde habían sido educadas en la misión y desde donde se habrían ido alrededor de 1870 . Su regreso a Queule se habría producido en 1875, ya como profesoras. Otro estudio, que no proporciona su fuente, anota las fechas de la presencia de las hermanas en Santiago y con alguna ambigüedad parece asociarlas a la publicación del Chilcatun y del Manual de Piedad:

las Hermanas de la Providencia, además de formar en 1875 en el Asilo del Salvador en Santiago a María Francisca y María Juana Cullfinhuanco [sic] como profesoras que ejercieron en Queule y Bajo Imperial, publicaron en 1899 un Manual de piedad en castellano y mapudungun que "contiene lo principal que debe saber y rezar un cristiano" y un Silabario bilingüe con la tradicional cartilla catequística (García 46).

Habiendo transcurrido entonces más de veinte años entre su residencia en Santiago y la fecha de publicación del Chilcatun, difícilmente pudieron participar en la confección de este documento, aunque cabe imaginar que su presencia en Santiago haya servido para fomentar el proyecto y quizás incluso la iniciativa de abrir escuela en Temuco.

A estas alturas de nuestra investigación, y con la información que tenemos, postularíamos entonces una autoría colectiva del Chilcatun: alguna de las monjas que estaban aprendiendo o que habían aprendido mapuzugun, alguna de las alumnas mapuche y Anselmo de Kamin, gracias al ímpetu de sor Mectilde, y con el beneplácito de Lenz. El Manual de Piedad, del mismo año, pudiera también tener características similares en cuanto a autoría. El hecho de que, como se verá, los textos para lectura que contiene el Chilcatun provengan de las obras de Andrés Febrés y de Rodolfo Lenz sugiere una confección cercana a una cultura de libros más que a una experiencia de aula. Al respecto, hay que recordar que, para la fecha de publicación de la obra, Kamin llevaba solo dos años en la región, por lo que su conocimiento 
activo del mapuzugun puede haber sido limitado. Por otra parte, la pista de las hermanas Kallfüñamko, que habría que seguir, por ahora es indicativa del interés que pudiera haber nacido tempranamente en la casa de Santiago por contar con un instrumento de alfabetización y primera formación lectora para la infancia mapuche.

\section{DESCRIPCIÓN DEL CHILCATUN}

El ejemplar que consultamos forma parte del acervo documental del Museo Bartolomé Mitre, en Buenos Aires ( $\mathrm{n}^{\circ}$ de registro 4193). Tiene 35 páginas y mide 19 centímetros de largo. La encuadernación es sencilla. Lleva en el lomo, con letras doradas, el título Chilcatun. Chile Dugnu.

En la portada, en blanco y negro, se lee en mapuzugun y mayúsculas Chilcatun $^{5}$, y en letra más pequeña, también en mayúscula, el subtítulo Chile Dugnu ${ }^{6}$. Al centro, el escudo nacional en su primera versión (antes de que se le colocara el lema actual) y al pie: "Santiago de Chile. Imprenta de San José. Casa Central de la Providencia, 1899”. A continuación, la página de créditos contiene la leyenda: "Primera Edición. Revisada por el Dr. D. Rodolfo Lenz". No lleva indicación del número de ejemplares, pero la mención de "primera edición" sugiere que se pensó de inmediato como una obra que tendría continuidad.

Varios son los elementos de la portada que nos parecen dignos de ser analizados. Ante todo, el hecho de que el título de esta cartilla esté en mapuzugun, ya que las cartillas de otras lenguas que hemos podido cotejar con esta llevan los títulos en castellano ${ }^{7}$. En segundo lugar, se advierte que el subtítulo Chili Dugnu reproduce casi al pie de la letra el que empleó el jesuita Havestadt para su gramática en 1777 (Chilidugu). Finalmente, la inclusión del escudo nacional es también sorprendente en un texto como este, pues en su lugar esperaríamos más bien una imagen religiosa. La composición de esta portada no parece del todo casual, por cuanto ofrecería una representación

\footnotetext{
La palabra chilcatun (trad.: lectura o escritura) está compuesta de chilca y el morfema verbal mapuche -tun. Chilca es un quechuismo en el mapuzugun (Sánchez 365).

Trad.: Habla o lengua de Chile.

Al menos es el caso de las cartillas de la misma época que hemos podido consultar en repositorios digitales.
} 
gramatical, fonética y simbólica de la nación. La asociación que puede hacerse entre Chilcatun (que, a pesar de no relacionarse con el nombre del país, contiene el sonido 'chil'), Chile Dugnu (literalmente "la lengua, o habla, de Chile") y el escudo nacional sugiere la intención -ingenua tal vez, pero no menos significativa- de colocar esta obrita, lingüística y políticamente, al amparo de la república y de afirmar su pertenencia al proyecto nacional de educación; cosa, por demás, natural si fue, como pensamos, financiada por el gobierno o si se publicó sin este financiamiento pero confiando en obtenerlo para las futuras ediciones.

Siguiendo con el análisis de aspectos visuales y simbólicos, las ilustraciones que figuran en el texto son nueve y se repiten. Puede ser que el catálogo que tenía la imprenta no haya sido muy extenso, pero también el espacio reducido debió limitar el número y tipo de ilustraciones. Sea como fuere, salvo una, no se han seleccionado por motivos estéticos sino que corresponden generalmente a los temas tratados en las páginas en que figuran, aunque no alcanzan el valor pedagógico que tienen las ilustraciones en el Nuevo Método de Matte, por evocar un contemporáneo. No obstante, vale la pena observar que la ilustración de los caballos de carreras que figura al pie de la página 11 corresponde a la palabra yomgen (domar) en la misma página, y que las ilustraciones identificadas en mapuzugun como ruka (casa mapuche hecha de elementos vegetales) y wampo (embarcación hecha de un tronco vaciado), que muestran una casa de dos pisos, de características europeas, y una goleta de tres mástiles respectivamente, también coinciden con la información dada en las páginas. No puede decirse, entonces, que sean aleatorias; al contrario, parecen escogidas para proyectar una representación de actualidad de la lengua.

El texto comienza en la tercera página, donde se repite el título y presenta la primera parte (Huude Huudam). Sin transición, se presentan los siete grafemas vocálicos, primero aislados y después sus combinaciones; esto es, los diptongos que hay en la lengua mapuche, sin ejemplificación. Se trata, por lo tanto, de un primer apresto a la lectura a partir del reconocimiento de los grafemas aislados. Se presentan luego sus formas mayúsculas y minúsculas, en letra de imprenta redonda y en cursiva. Entre la página 4 y la 11 se exponen los 25 grafemas consonánticos, siguiendo un patrón recurrente: su escritura en mayúscula y minúscula, su combinación con las vocales, su uso en algunos diptongos y, finalmente, algunas palabras de ejemplo, separadas silábicamente por guiones. La página 12 muestra ya todas las letras, en mayúscula y minúscula, en orden alfabético y completa la página una lista de palabras ejemplo que comienzan con cada uno de los grafemas propuestos. 
Todas las palabras forman parte del léxico patrimonial del mapuzugun, excepto algunos castellanismos naturalizados (ofisa, manso, tafla $)^{8}$. La página siguiente introduce los numerales en mapuzugun, acompañados de su representación en números arábicos. Posteriormente, se muestran todas las letras del silabario en letra ligada, en mayúscula y minúscula, acompañado de ejemplos. Con esto finaliza esta primera unidad, en la que, por lo que podemos deducir, el niño debe familiarizarse con la lectura y escritura en su propia lengua, el mapuzugun. Es en la segunda parte (Epulelu Huudam) que se lleva al alumno hacia el castellano no, como podría pensarse, mediante el alfabeto completo, sino usando un atajo: bajo el subtítulo Huinca dugnu m'ley t'fa ("en castellano está esto") (p. 15) se introducen los grafemas que representan sonidos que el mapuzugun no utiliza o que representa de otra forma: $<\mathrm{b}>,<\mathrm{j}>,<\mathrm{k}>,<\mathrm{v}>,<\mathrm{x}>\mathrm{y}<\mathrm{z}>$, cada uno en mayúscula y minúscula. Esto reafirma que el estudiante no parte del castellano, sino del mapuzugun en su proceso de alfabetización. En la página siguiente figuran palabras en castellano silabeadas, que ilustran algunos de estos sonidos, y así continúa en la otra página, donde se presentan ejemplos con casi todas estas letras "nuevas" ("bue-no blan-co bru-jo", por ejemplo). Luego, en la página 17, el contenido que ya se vio en mapuzugun (p. 13): los numerales, ahora en castellano. Sin transición, comienzan en la página 18 las lecturas para ejercitación. Son en total tres secciones de extractos de textos sencillos, que describimos en el siguiente apartado.

\subsection{INTERTEXTUALIDAD: INTERPRETACIONES SOBRE UN RECICLAJE}

El Chilcatun es una obra pedagógica, para alfabetizar y enseñar a leer sobre la base de textos de contenido religioso-moral. En su aspecto discursivo, como hemos dicho, nos parece de interés poderlo vincular al Manual de Piedad, por la parte religiosa, pero también nos parece que tiene afinidad con el Nuevo Método de Matte, basado en la experiencia alemana del autor, y, en tal sentido, se explicaría que el Chilcatun haya interesado a Rodolfo Lenz, quien, como se ha dicho, lo patrocina abiertamente. 
Entre las páginas 18 y 35 se encuentran los fragmentos para lectura, en presentación bilingüe a dos planas, en castellano en la página impar y en mapuzugun en la par. El contenido de las lecturas es moralizante y religioso, busca regular las conductas y promueve en varios pasajes la lectura, la escritura y la escolarización. Temáticamente podemos distinguirlos de la siguiente manera: una primera sección, sin título (pp. 18-23), se compone de tres escenas de la vida cotidiana, en forma de diálogo, y un fragmento de relato, numerados del I al IV. Le sigue la sección titulada Trrocom pichi que che tañi quimael t'fachi dugnu / "Los niños deben saber que" (pp. 24-29), con frases para aprender los nombres de los meses, estaciones del año y días de la semana, en ambas lenguas. La tercera sección (pp. 30-35) se compone de seis textos de carácter moral, numerados del 1 al 6, y finaliza con la sentencia Fill ant' eluafiyim mañum c'me Dios eluqueeyim mew fill dugnu, traducida como "Todos los días debemos dar gracias al buen Dios que nos da tantas cosas", seguido de $A f i$, y su traducción: "Fin".

Los textos, como se verá a continuación, no fueron en su mayoría concebidos para la cartilla sino que provienen de otras fuentes. La sección primera, efectivamente, tiene como hipotextos fragmentos de los diálogos ficticios que Rodolfo Lenz, con la colaboración de Víctor Chiappa y del misionero anglicano Carlos Sadleir, elicitaron en mapuzugun siguiendo el modelo de Ernst Middendorf en su obra Die Aymará Sprache (248-269) Lenz presentó ese material en castellano a sus colaboradores indígenas Calvun (Segundo Jara), para la variante pewenche; Juan Calvun, para la variante moluche; y Domingo Quintrupai, para la williche, para que dieran sus versiones respectivas, que son las reproducidas en los estudios II, III, V y XII, respectivamente. En el Chilcatun, de los hipotextos que se reproducen a la letra, todos corresponden a la variante pewenche, salvo un caso, que reproduce la variante moluche. En la segunda sección, de textos morales, hemos identificado como hipotextos algunas "Pláticas" que forman parte del Arte de Febrés (1765).

A continuación transcribimos los hipotextos de estas lecturas del Chilcatun, que se pueden comparar con el texto original (ver Documento):

9 Para mayor información, véase la web dedicada a los Estudios Araucanos de Rodolfo Lenz: www.estudiosaraucanos.cl 
Chilcatun, Primera sección, I, pp. 18-19 = Estudios araucanos, XII. Diálogos moluche (numeración del original):

108. ¿Dónde has estado, muchacho? - No he salido; he estado aquí. ¿Cheumlepeimi, pichi che? -T'ipapelan, vau ta mlekapen.

109. Dices una mentira. Te he llamado en todas partes y no me has oído.

Koilatuimi. Müt'ümkiyaulpeyu, aরkülaimi məlepürkeরeel.

110. Dime siempre la verdad; porque si mientes tengo que castigarte. Vei pien, küme duņune; koillatulmi kewayayu.

Chilcatun, Primera sección, II, pp. 18-19 = Estudios Araucanos, V, Diálogos pewenche (numeración del original):

62. ¿Sabes escribir o leer?

¿KimchiKkatuimi am kai?

63. No, señor; no sé escribir; pero un poco sé escribir; pero un poco

sé leer. Kimchißkatulan; livru-mu pachi kimfun.

64. ¿Puedes leer este papel? ¿Entiendes lo que dice?

¿Tavachi papil duñulavuimi? ¿Kimimi tañi chem pin anchi

65. No lo comprendo. Está mal escrito.

Kimlaviñ, matt'e weda chiKkatunņei.

66. ¿Quieres aprender a escribir, si yo te enseño?

Kəpa-kimkeimi chiKkatun am, iñche kimelaveyu.

67. Con mucho gusto, señor; pero me temo que soy muy torpe.

Fen·tepun ayüufun; matt'e ül·ņum n̦en.

Chilcatun, Primera sección, III, pp. 20-21 = Estudios Araucanos, V, Diálogos pewenche (numeración del original):

284. Este hombre tenía cinco hijos, dos niñas y tres muchachos.

Təvachi went'u niekevui kechu pəñeñ, epu ñawe, kəla vottəm.

285. Pero dos muchachos murieron; se ahogaron cuando querían pasar el río en invierno.

Feimeu epu vottam lai, ürfi leuvu-meu, rumepelu puk·em.

286. La corriente fue muy fuerte y se los llevó río abajo.

Ventepun wit'ui təveichi leufu; feimu yeņei, nakəmeyu wit'un leufu. 
287. Yo quería salvarlos, pero no podía.

Inche kapa-nentufuiñ eņu, pepi-nentulaviñ eņu.

288. Poco faltaba que yo también me ahogara.

Pachin-muevui ñi ürfiael kai.

Chilcatun, Primera sección, IV, pp. 20-23 = Estudios Araucanos, V, Diálogos pewenche (numeración del original):

313. ¿De quién es este caballo? ¿Es el tuyo?

¿Iñei ñi kawel tafei? ¿Eimi anchi?

314. No, señor; es el caballo de mi hermano; solo el freno que lleva es mío.

Inche no; tafachi kawe氏́ ñi peñi;piiña matten inche.

315. Mi hermano y yo vivimos en una misma casa, allá al pie del cerro; pero yo no uso sus caballos de él, y él no debe tomar las frutas de mis manzanales.

Ñi peñi inche maleyu kiñe ruka-meu; tiyechi mawida-meu male iruka.

Inche parañmakelavin ñi kaweরu: ñi peñi kai konpakelai ñi mánchana-meu.

316. Así vivimos muy contentos cada uno con lo suyo.

Feimeu maleyu ayukaleyu,kizu ke nieyu duņu.

317. Ese hermano, de quien hablas ¿es mayor que tú, o no?

Təfei mi peñi wünen, ¿inan anchi?

318. Sí señor; es mayor; pero tengo también un hermano menor, que vive en la casa de mi tío.

Felei, wünen ta tei. Inche nien kiñe peñi inan kai inche-meu. Fei ñi ruka ñi maরe-meu.

319. Ese chico va a la escuela desde dos años, y ya sabe escribir y leer.

Fei tavichi pachilu epu t’ipantui eskuela-meu kimuchiאkatun.

En cuanto a la tercera sección del Chilcatun, los textos numerados 1 y 2 tienen como hipotexto las "Pláticas", o sermones breves, del Arte de Andrés Febrés (1765), adaptada la ortografía como en las secciones anteriores. Los textos 3 y 4 , sin ser extractos textuales, puede que contengan elementos de las mismas. Desconocemos el origen del fragmento 5, que temáticamente podría vincularse al Sermón $5^{\circ}$ de Luis de Valdivia (1621) o a las Pláticas 383 y 384 de Febrés. 
A continuación, presentamos y comentamos los hipotextos confirmados o supuestos:

\section{Chilcatun, Tercera sección, 1, pp. 30-31 = "Pláticas" (Febrés, Arte, numeración del original):}

"381 - Quimaymn may tvfachi unen Coyagh meu, ñi mleel ta quiñe Dios, iney cam ta Dios, chumi cam cuyvi, chumquey ado, chumay cay ula ta, quimaymn. Quiñe Dios gey may, vill pepilvoe, vill mapu mo mlequelu cav: Huenu mapu, Tue mapu, vill caque dugu vemvoe, thoquiquevilu cay.

381 - Habeis de saber pues en este primer razonamiento, que hay un Dios, quien es Dios, sabréis lo que hizo antiguamente, que hace ahora, y que hará después. Un Dios hay pues todo poderoso, que todo lo sabe, y que està en todo lugar: hacedor del Cielo, de la Tierra y de todas las demás cosas, y que lo gobierna."

Chilcatun, Tercera sección, 2, pp. 30-31 = "Pláticas" (Febrés, Arte, numeración del original):

"382 - Tvachi cùme Dios cheuquechi rume mlequey, Hиепи mapu meu, Tue тари теи, ри тіпи lavquen теи, ри lеиvи теи, ри rиса теи, сhеи то ruте mlequey ta Dios: vey tañi vla vill gamn piuque, vill gamn duamtuel cay, pequevi ta Dios, uthintuqueavi cay: quiñe che tañi huerilcayal, el caule rume, pequeyen ta Dios, uthintuqueyeu cay; cheu mo no rume pepi elcauquelaiñ Dios ñi age meu, vill ple mlequelu.

382 - Este buen Dios está en todas partes, en el Cielo, en la Tierra, dentro del mar, en los rios, en las casas, en cualquier lugar està Dios: por esta causa todos vuestros pensamientos, vuestros corazones, todo lo que pensais, y haceis lo està viendo Dios, y lo està mirando: por mas que se esconda un hombre, para pecar, lo està viendo Dios, y lo està mirando; en ninguna parte nos podemos esconder de la cara de Dios, que en todo lugar està."

\section{Chilcatun, Tercera sección, 3, pp. 32-33 "Pláticas" (Febrés, Arte).}

En Febrés hay frases similares en la Plática 396, pero solo "Fill fun mamul m'lelu tat'fa mapu meu iduamfilmu yafilmu, huelo quiñe mamul ragniclelu ilayafimu" podría reconocerse, con algunas variaciones, en el Chilcatun: "Vill vachi vùn mamull, iduamvilmu, iavimu, inche, ga maypiuqueiñ, quiduduaтаути еутu, huelu re quiñe vùn mamull raginclelu, ilayavimu". Sin embargo, la similitud podría también deberse a que se trata de una oración 
fijada por la tradición. Llama la atención en ambas el verbo "criar" en lugar de crear, cosa que está también en Febrés (Dios es "criador", no creador). Podría, por lo tanto, tratarse de una adaptación de Febrés o bien de algún devocionario antiguo.

\section{Chilcatun, Tercera sección, 4, pp. 34-35 "Pláticas" (Febrés, Arte).}

En Febrés, Plática 386, se lee: "Pu Anghel Espiritu geygn taiñ pulli vemgelu; huelu an [¿?] genolu. Pu Anghel vill mlequelay Huenu meu: Dios eleyeuvillegn Hиепи тари теu", con lo que tendríamos como idéntica la primera frase: "Los ángeles son espíritus como el alma y no tienen cuerpo". Luego, en lugar de "ven siempre a Dios en el cielo", Febrés escribe: "no están todos en el cielo". Hay un cierto paralelismo de construcción que hace suponer que al menos se tenía a la vista las Pláticas también en este caso.

Como hemos señalado, la selección de los textos es propia de las temáticas de los catones: pequeñas instrucciones destinadas a inducir la moralidad en las conductas y reforzar el adoctrinamiento religioso. La intertextualidad en el Chilcatun no es novedosa, y tampoco es novedoso que no se explicite ni se mencione el origen de estos ejemplos de discurso ${ }^{10}$, pues funcionan como meros apoyos o ejemplos que ilustran y transmiten lo esencial: las pautas de conducta que debe adquirir el niño mapuche y los principios cristianos que después se cimentarán por medio de lecturas más extensas, como las del Manual de Piedad. En este caso, sin embargo, es digno de señalarse que la selección de frases de Estudios Araucanos tiene más una intención pedagógica que propiamente moral. En uno de los fragmentos se representa claramente la sociedad de transición: de los tres hermanos, el mayor sigue pensando en caballos, como un mapuche del campo, mientras que el menor ya va a la escuela y sabe escribir; son dos mundos, y el que enuncia las frases es un hermano de en medio, situado así entre la tradición y la modernidad, como una metonimia de la sociedad misma. La experiencia de la escuela, con sus dosis de castigos y premios, y la relación novedosa del niño con un educador extraño, son otros temas que aborda la ejemplificación tomada de la obra de Lenz. Los fragmentos de Febrés pertenecen todos a la Plática I, sobre "Dios

10 El silabario de Matte (38-56) contiene, sin identificarlos como tales, fragmentos de traducciones de nütxam mapuche como textos de lectura en castellano. Estos nütxam son tomados de la Gramática de Félix de Augusta (336-340). 
y la Creación del Mundo", y posiblemente hayan sido seleccionados porque contienen las nociones primeras de catequesis, fáciles de leer y asimilar.

\subsection{DECISIONES ORTOGRÁFICAS: ¿EN BUSCA DE UN CANON PARA EL MAPUZUGUN?}

Aunque los datos que aportan el Chilcatun, así como el Manual de Piedad y la correspondencia de Lenz no permiten dilucidar cuán importante fue el papel de este como "revisor", quisiéramos proponer en este trabajo que, además de la inclusión de los textos de sus Estudios Araucanos, el diseño del sistema de escritura que se utiliza en la cartilla permite identificar algunas de las ideas e ideologías de Lenz con respecto a la escritura y la ortografía. Según observamos, el sistema de escritura utilizado es exclusivo de este material, por lo que, al no haber otros similares o iguales, puede suponerse que esta alfabetización en mapuzugun está destinada meramente al desciframiento del Manual de Piedad. La cartilla no incluye paratextos que puedan arrojar luz al respecto, pero en las "Advertencias" del Manual de Piedad se da la explicación del sistema de escritura y ahí es donde nos parece poder identificar algunas de las posturas de Lenz que también se materializaron en el Chilcatun.

Como ha señalado Pavez (14), los debates sobre la reforma ortográfica en Chile son bastante sugerentes para la comprensión de su contraparte contemporánea sobre la normalización alfabética del idioma mapuche. Aunque el debate sobre la ortografía en Chile se da fundamentalmente entre 1830 y 1850 (véase Contreras; Arnoux), al momento de intervenir Lenz, en la década de 1890, las polémicas ortográficas empezaban a cobrar nuevas fuerzas (Cáceres y Rojas 71). La postura que Lenz sostiene en la disputa pública entre los partidarios de la ortografía reformada chilena y los adherentes a la ortografía de la Real Academia Española está fundada en una ideología lingüística (Del Valle y Meirinho-Guede) que está presente en sus textos tanto sobre la escritura del castellano (Lenz, "De la Ortografía" y "Observaciones") como del mapuzugun (Lenz, Estudios).

La postura de Lenz se sostiene en la ciencia lingüística, desde donde construye su autoridad. De acuerdo a esta perspectiva era preferible la ortografía reformada chilena, en tanto "es mucho mas científica, lójica i fácil que la de la Real Academia Española" (Lenz, "De la Ortografía" 568). Al posicionarse desde el saber científico, la decisión de Lenz responde al ideologema de la razón que rige la política educativa en el contexto de modernización del Estado sobre bases científicas y positivistas (Cáceres y 
Rojas 76). El financiamiento gubernamental de la publicación del Manual de Piedad y, posiblemente, del Chilcatun ${ }^{11}$ sería prueba de esta concordancia de intereses. El discurso de la ciencia, en este caso, postulaba que "la ortografía ideal debe atenerse a la pronunciación, en congruencia con la idea de que las lenguas son primero que nada manifestaciones orales, establecida como axioma por el paradigma lingüístico hegemónico del último cuarto del siglo XIX" (Cáceres y Rojas 77). El carácter "fonético" de esta ortografía ideal, que hoy llamaríamos "fonémica", queda establecida en un punto de Lenz: "Con esto queda incontestablemente establecido que la ortografía ideal tiene que ser una escritura fonética, en la cual a cada sonido corresponda un solo signo gráfico i a cada signo gráfico un solo sonido pronunciado (Lenz, "Observaciones" 571, cursivas en el original).

La idea del fonetismo aparece tempranamente en los estudios de Lenz sobre el mapuzugun, marcados también por una atención particular a la variación dialectal. Así, en el primero de sus Estudios Araucanos ("Viaje al país de los Manzaneros (huilliche)") señala:

En cuanto a la ortografía, ya he dicho que es fonética i no he uniformado nada. Quienquiera que haya estudiado un dialecto vivo, sabe que toda lengua no fijada por literatura escrita no presenta sonidos i formas completamente fijas, i en cada dialecto hai ciertos sonidos i ciertas formas especialmente inclinadas a vacilaciones (5-6, las cursivas son nuestras).

La escritura "fonética" y la no uniformidad le permiten representar gráficamente la variación y las diferencias dialectales entre los textos que registra. Ahora bien, al carecer el mapuzugun de "una literatura escrita", no existe una norma supradialectal que se represente en la escritura como sucedería con el castellano, lo que impone, por tanto, otro régimen ortográfico (Sebba 41-45). La distancia entre el régimen no fijo del mapuzugun y el espacio regulado de la escritura en castellano lo establece la existencia de una norma. Esto es, si la ortografía debe representar la pronunciación, esta no será "la pronunciación individual de un solo hombre, sino aquel cánon de pronunciación que se forma por la abstracción de todas las peculiaridades

11 En la portadilla del Manual de Piedad, se lee: "Edición revisada por el Dr. Don Rodolfo Lenz y costeada por el Supremo Gobierno". En la página de créditos del Chilcatun solo aparece "Primera edición, revisada por el Dr. D. Rodolfo Lenz". 
individuales que no coinciden con el término medio usado entre los hombres instruidos de una comunidad lingüística" (Lenz, "Observaciones" 571, las cursivas son nuestras). Para la existencia de este "cánon de la pronunciación", sin embargo, es necesario que la lengua estuviese "fijada por literatura escrita", como una condición concomitante de la conformación del grupo de los "hombres instruidos".

Sin embargo, en el diseño de un instrumento como una cartilla de enseñanza de lectoescritura se ingresa a un espacio de instrucción que exige un régimen ortográfico regulado y normativo; una lengua "fijada por la literatura escrita". Por eso se establece un repertorio de letras y sonidos acotado, que en este caso hace uso extensivo de dígrafos y trígrafos, lo que, aunque no presenta problemas para los actuales métodos fonéticos de enseñanza ${ }^{12}$, sí complejiza la escritura y va contra el principio señalado por Lenz, según el cual "a cada sonido corresponde un solo signo gráfico i a cada signo gráfico un solo sonido pronunciado". La presentación de esta ortografía soluciona, de cierta manera, esta inconsistencia:

Destinado el presente "Manual" para la enseñanza de los Mapuches y no teniendo su idioma ninguna ortografía escrita, ha parecido conveniente escribirlo de la manera más sencilla posible. En conformidad a esto, se ha usado de la ortografía castellana en lo que tiene de más fonético y racional; por lo cual será la lectura del mapuche sumamente fácil para los que hablan el castellano. Las diferencias se reducen solamente a las siguientes: $1^{\circ}$. La combinación gn es uno de los sonidos más característicos del mapuche, $\mathrm{y}$, aunque escrito de diversas maneras por los araucanistas, nos parece que, tal como se usa en toda esta obrita, se acerca más a la verdadera pronunciación de los indígenas y a la ortografía castellana. Sin embargo, hay que oírla de viva voz (Manual de Piedad VII-VIII, las cursivas son nuestras).

La señalada carencia que presentaría el mapuzugun con respecto a una "literatura escrita" se suple en parte con el uso de la tradición castellana, que representa la opción "más sencilla posible", particularmente con "lo

12 Recordemos que antes del método fonético, la enseñanza de la lectoescritura consideraba el nombre de las letras antes que su sonido, lo que resultaría improcedente con la escritura del mapuzugun en este caso. 
que tiene de más fonético y racional". En los casos en los que no es posible seguir esta tradición, y que corresponden a las "diferencias" entre una lengua y otra, se propone una representación escrita que conciliaría la "verdadera pronunciación" y la "ortografía castellana". Sin embargo, aconseja igualmente "oírla de viva voz". Tanto en la valoración positiva de lo "fonético y racional" como en esta última sugerencia, nos parece estar frente al Lenz que defiende la reforma ortográfica y al fonetista que viaja a la "frontera" para "buscar las fuentes vivas del idioma hablado" (Lenz, Estudios XX) y "oir hablar a los indios" (Lenz, Estudios IV).

Al momento de presentar los sonidos vocálicos, se presentan siete, tal y como los distinguen Lenz y otros araucanistas del periodo, aunque con otras representaciones gráficas. Un punto históricamente conflictivo en la descripción del mapuzugun ha sido precisamente el repertorio vocálico y la disputa sobre la sexta vocal (Dehnhardt, Valenzuela y Villarroel). Actualmente, la distinción que establece Lenz entre $<\ddot{\mathrm{u}}>\mathrm{y}<\boldsymbol{\partial}>$ se considera una sobrediferenciación fonética, innecesaria para una escritura práctica, en tanto son alófonos de un mismo fonema. Sin embargo, este punto es el que sostienen las críticas de Lenz para desautorizar la ortografía de Manquilef (Payàs, Ortiz y Sambolin):

Como la corrección de pruebas de este trabajo ha estado esclusivamente a mi cargo, tengo que declarar que, salvo algunos errores evidentes, no he alterado en nada la trascripción del señor Manquilef, aunque en muchos casos escribe indistintamente ya u, ya ü, donde Frai Félix i yo distinguimos $Ә[\ldots]$ R. Lenz. (Manquilef, “Comentarios II" 215).

Lenz hace el mismo comentario en 1911 (Manquilef, "Comentarios I" 2). La distinción acá igualmente se justifica y se representa como un apóstrofe y una $<\mathrm{u}>$, "que también otros han escrito como ú (confundiendo así en una sola letra dos sonidos)" (Manual de Piedad VIII, las cursivas son nuestras).

El uso de la ortografía castellana, además de salvar el escollo de la "tradición escrita" ya apuntado, presenta la ventaja de que "será la lectura del mapuche sumamente fácil para los que hablan el castellano". Aunque se declare que el uso es de lo "más fonético y racional", lo cierto es que hace distinciones innecesarias según estos principios, como es el uso de $<\mathrm{c}>\mathrm{y}<\mathrm{q}>$ para $/ \mathrm{k} /$, lo que parece justificarse en la conservación de ciertos usos "para evitar confusión”. La cercanía entre sistemas de escritura, en estos contextos, se suele interpretar con una intención de transicionalidad entre lenguas (Sebba 76-79); esto es, aunque esta alfabetización inicial sea en mapuzugun, la 
alfabetización "completa" será en el "idioma patrio". Por lo tanto, la elección más práctica en la correspondencia fonema-grafema sería aquella que es más similar al idioma en el que se realizará la alfabetización "completa". De esta manera, el uso de las convenciones ortográficas del castellano que no serían "fonéticas y racionales", vendría a confirmar el proyecto de transición que planteamos. Del mismo modo, el objetivo castellanizador es explícito en una crónica aparecida en un periódico no identificado, el 26 de octubre de $1901^{13}$, donde se indica que los estudiantes llegan a la escuela "sin saber el castellano, pero lo aprenden con una facilidad asombrosa. A este efecto se ha publicado un Chilcatun, silabario en mapuche y español" (las cursivas son nuestras).

La idea de transición está presente en el diseño mismo de la cartilla que, como ya señalamos, introduce en su segunda sección, bajo el subtítulo Huinca dugnum 'leyt'fa ("en castellano está esto"), los grafemas que representan sonidos que el mapuzugun no utiliza. La cartilla, entonces, permitiría una alfabetización simultánea en ambas lenguas y utilizando el mapuzugun inicialmente para llevar a los estudiantes hacia el castellano. Asociada a esta castellanización está también la corrección en la pronunciación, lo que se puede ver con la presentación en esta sección de algunas combinaciones gráficas del castellano que podrían confundirse con la pronunciación mapuche. Suponemos, entonces, que esto debe haber exigido una ejercitación y repetición oral constantes. Así, se presenta para el castellano el dígrafo $<\mathrm{rr}>$ y la combinación $<\operatorname{tr}>$. Su similar mapuche, sin embargo, se escribirá $<$ trr $>$, que "queda exactamente conforme con la verdadera pronunciación escrito así con doble r, que es como nuestro pueblo pronuncia las voces arancanas [sic]" (1899 VII $)^{14}$.

Otro punto interesante de este texto es la inclusión de varios fragmentos de los Estudios Araucanos de Lenz. Como ya se vio, el énfasis de Lenz en las diferencias dialectales permite asociar cada texto a un dialecto en particular. En el Chilcatun se recogen en su mayoría fragmentos que provienen de los textos pewenche, dialecto cuyo rasgo prominente es la realización sorda de los sonidos fricativos: "La gran lei fonética que distingue los dialectos del araucano se debe a la tendencia de cambiar $v, d, z h, z^{\prime}, l$ en $f, z, s h, s^{\prime}, l$ "'

13 "Araucanía" (véase nota a pie 3).

14 Esta convención ortográfica no aparece en los Estudios Araucanos de Lenz, pero sí en su Diccionario Etimológico donde indica que "algunos autores [...] han escrito el sonido $t c h$, lo que no tiene mucha ventaja sobre la notación $t r$; quizás sería preferible $t r r$ " (97). En la misma página identifica este sonido como mapuche, aunque también, señala, es preferido "entre la jente de poca instrucción". 
(Lenz, Estudios XXIII). En la escritura de este dialecto, Lenz utiliza $<\mathrm{v}>$ para el sonido que en otros dialectos representa como $<\mathrm{f}>$, como se ve a partir de la cita. Sin embargo, los textos pewenche que reproduce el Chilcatun aparecen todos normalizados bajo la escritura con $\langle\mathrm{f}\rangle$, incluyendo los fragmentos de las Pláticas de Febrès, cuya escritura original alterna $v$ y $f$. Esta estandarización puede entenderse como una forma de acomodar la escritura al dialecto más cercano a Temuco, donde está precisamente la escuela de las Hermanas de la Providencia.

La valoración y visibilidad política que alcanzará esta variante local se inserta dentro de un proceso de transformaciones sociales en el que confluyen diversos factores. Entre estos, no se puede descartar el surgimiento y consolidación de una "élite" bilingüe de hijos de $\log k o^{15}$ y su posicionamiento en las instancias oficiales de mediación intercultural. Previamente a la ocupación definitiva del territorio mapuche por parte del Estado chileno, y refiriéndose a las transformaciones sociales que llevan a la desaparición de los funcionarios llamados "de amigos" en el contexto posreduccional, un estudio reciente señala que

varios de estos funcionarios se mostraron más próximos a la estrategia política de resistencia desplegada por los arribanos y llanistas encabezados por MagilWenu, varios fueron perseguidos y progresivamente reemplazados en sus funciones por sujetos de mayor confianza: los hijos de los lonkos más cercanos a la República, especialmente en la provincia de Malleco y en las proximidades de las ciudades como Temuco fundadas hacia fines de siglo (Pavez, Payàs y Ulloa 175, las cursivas son nuestras).

Estos elementos, así como la paulatina consolidación de Temuco como centro urbano y capital administrativa, podrían explicar esta normalización ortográfica de los textos, de modo que correspondieran al "término medio usado entre los hombres instruidos de una comunidad lingüística", como mencionaba Lenz, identificando como tal el dialecto de cierto grupo en específico. Es decir que si el "canon de pronunciación" no puede establecerse en base a una tradición escrita, sí podría construirse tomando como base los rasgos dialectales asociados a los grupos que, debido a las transformaciones 
de este periodo, quedan más cercanos al poder político y a las instituciones mediadoras.

\section{CIERRE}

Cuando se publica este Chilcatun, en las instancias de gobierno y en las sociedades científicas se está debatiendo sobre si los mapuche son o no civilizables, si pueden o no integrarse a la nación y qué lugar puede haber en la república para su cultura.

El Chilcatun, producto de lo que parece haber sido la colaboración entre un cura capuchino alemán y unas monjas de una congregación canadiense que tenían a su cargo unas niñas mapuche, fomentado por una madre superiora que debió tener una visión más amplia que muchos laicos de la época, y auspiciado por Lenz, el máximo estudioso del mapuzugun es una muestra de lo que en ese lugar y tiempo alguien pensó posible: que el mapuzugun se podía escribir y leer, que en él se podía aprender y que era homologable al castellano pues eran intertraducibles. Y, además, que por el mapuzungun se podría llegar más fácilmente al castellano que si se negaba la identidad lingüística indígena, pues hay que advertir que en la cartilla el mapuzugun no es reemplazado por el castellano, sino comparado con él y conservado hasta la última página.

Así pues, esta cartilla, modesta como es, parece inscrita en una red de prácticas y discursos que articulan la lengua, su representación ortográfica, la escritura, la lectura y la educación en un contexto en el que todo le es adverso al mapuzugun. Su carácter excepcional no se debe solo a que sea el único instrumento de este tipo del que se tiene registro, tanto para el periodo estudiado como para el mapuzugun en general, sino a que entrega claves para entender la circulación del alfabeto y la castellanización que se da tras la incorporación militar del Wallmapu, así como las formas en que se llevó a cabo la enseñanza en las aulas. Abre la posibilidad de que no solo se haya alfabetizado en español, u obliga a considerar que puede haber habido formas de alfabetizar distintas ya sea por épocas, por territorios o quizás por órdenes religiosas.

En cuanto a su valor dentro del archivo mapuche, se puede decir que, si el afán del giro escritural supone una desclasificación de documentos, este en particular proyecta la posibilidad de la escritura ya sea en mapuzugun o en 
castellano y, por tanto, también la existencia de un corpus de escrituras privadas o públicas hasta ahora desconocidas. Por otra parte, nos parece importante destacar el lugar del archivo del que da cuenta este texto, pues, a contrapelo del relato habitual, se trataría de un colegio no directamente misional, sino que urbano y fundamentalmente femenino, tanto en las estudiantes como en el personal religioso. La existencia de un documento como el Chilcatun obliga a replantear si en todo tiempo y lugar la alfabetización se hizo en favor del español, "mientras que la lengua originaria se mantenía fuera del alcance de las prácticas de literacidad" (Malvestitti, "Nahuelpi" 3). En definitiva, el uso escolar de este instrumento de enseñanza supone necesariamente el despliegue de distintas prácticas letradas en ambas lenguas y, por lo tanto, reafirma la existencia en la época de usuarios mapuche del alfabeto. Y afirma también la intención de normalizar la escritura del mapuzugun al optar por una representación ortográfica que, representando quizás el sector más sobresaliente de la sociedad mapuche, pudiera ser admitida con más facilidad.

El hecho indiscutible del retroceso en el uso del mapuzugun por las políticas de castellanización forzada debe ser comprendido en toda su complejidad, con sus tendencias doxológicas y también con sus rupturas y contradicciones. También conviene que los agentes y sus actuaciones sean analizados desde esta perspectiva crítica. Esperamos, así, aportar con este trabajo a la comprensión de las operaciones de mediación y traducción, en un sentido amplio, que operan en el proceso de radicación de los mapuche en comunidades y su interacción con las ideologías lingüísticas de la época.

\section{BIBLIOGRAFÍA}

Anónimo. Manual de Piedad en castellano y en mapuche (araucano) para texto de lectura de los indigenas de Chile. Santiago, Imprenta de San José, 1899.

Araya, Nicole. Escolarizados y virtuosos. Niñas y niños representados en los silabarios $y$ textos de lectura (1840-1900). Santiago, Ediciones Museo de la Educación Gabriela Mistral, 2020.

Arnoux, Elvira. Los discursos sobre la nación y el lenguaje en la formación del Estado (Chile, 1842-1862). Estudio glotopolítico. Buenos Aires, Santiago Arcos, 2008.

Augusta, Félix. Diccionario Araucano-Español, Español-Araucano. (Dos tomos). Santiago, Imprenta Universitaria, 1916.

CÁceres, Valentina y Darío Rojas. "Rodolfo Lenz y la reforma ortográfica chilena: ciencia, tradición y política del lenguaje”. Boletín de Filología 54, N¹, 2019, pp. 65-93. 
Cáceres, Valentina, José M. Ortiz y Darío Rojas. "El Diccionario etimológico de Rodolfo Lenz (1905-1910): una aproximación glotopolítica”. Boletín de Filología 55, №1, 2020, pp. 13-49.

Chartier, Anne-Marie. Enseñar a leer y escribir: Una aproximación histórica. Ciudad de México, Fondo de Cultura Económica, 2004.

Contreras, Lidia. Historia de las ideas ortográficas en Chile. Santiago, DIBAM/ Centro de Investigaciones Diego Barros Arana, 1993.

Dehnhardt, Macarena, Adrián Valenzuela y Natalia Villarroel. “Adaptación de la sexta vocal /ü/ del mapudungun al español de Chile. Una revisión del Diccionario Etimolójico de Rodolfo Lenz". Tesis de Licenciatura en Lengua y Literatura Hispánica mención Lingüística. Universidad de Chile, 2015.

Del Valle, José y Vitor Meirinho-Guede. “Ideologías lingüísticas”. Enciclopedia de Lingüística Hispánica. Vol. 2. Javier Gutierrez-Rexach (coord)., Londres, Routledge, 2016, pp. 622-631.

Demerson, Paulette. "Tres instrumentos pedagógicos del siglo XVIII: la Cartilla, el Arte de escribir y el Catón". L'enseignement Primaire en Espagne et en Amérique Latine du XVIIIe siècle à nos jours : Politiques éducatives et réalités scolaires. Jean-René Aymes et al., Tours, PressesUniversitaires François-Rabelais, 1986, pp. 31-40. Web. <http://books. openedition.org/pufr/5182>.

Donoso, ANDRÉs. Educación y nación al sur de la Frontera: Organizaciones mapuche en el umbral de nuestra contemporaneidad, 1880-1930. Santiago, Pehuén, 2010.

Durán, Teresa y Nelly Ramos. "Castellanización formal en La Araucanía a través de la escuela”. Lenguas Modernas 15, 1988, pp. 131-154.

EnNis, JuAn y Darío Rojas. "Introducción. Rodolfo Lenz revisitado: un vector glotopolítico en un país en modernización”. Boletín de Filología 55, №2, 2020, pp. 11-32.

Febrés, Andrés. Arte de la Lengua General del Reyno de Chile, con un diálogo chileno-hispano muy curioso, a que se añade La Doctrina Cristiana, esto es, Rezo, Catecismo, Coplas, Confesionario y Pláticas; lo más en Lengua Chilena y Castellana, y por fin un Vocabulario Hispano-Chileno, y un Calepino Chileno-Hispano más copioso. Lima, s/d, 1765.

Diccionario hispano-chileno (Enriquecido de voces i mejorado). Edición de

Antonio Hernández Calzada, Santiago, Imprenta del progreso, 1845.

Flores, JaIME y Alonso Azócar. Evangelizar, civilizar y chilenizar a los mapuches. Fotografías de la acción de los misioneros capuchinos en la Araucanía. Temuco-Sevilla, Ediciones Universidad de La Frontera/Editorial Universidad de Sevilla, 2015.

García, EnRiQue. "Las congregaciones religiosas en la historia de la educación chilena". Pensamiento Educativo 42, N¹, 2008, pp. 43-56.

Guevara, Tomás. Costumbres Judiciales i Enseñanza de los Araucanos. Santiago, Imprenta Cervantes, 1904.

Havestadt, Bernardo. Chili-dugu sirve tractatus linguae chilensis. 1777. Leipzig, Edición de Julius Platzmann, 1883.

Hermanas de la Providencia. La congregación de las Hermanas de la Providencia de Chile. Santiago, Imprenta de San José, 1924. 
Lenz, Rodolfo. "De la ortografía castellana". Anales de la Universidad de Chile LXXXVII, 1894, pp. 559-569.

"Observaciones sobre la ortografía castellana". Anales de la Universidad de Chile, LXXXVII, 1894, pp. 570-579.

Estudios Araucanos. Santiago, Imprenta Cervantes, 1895-1897. Versión electrónica a cargo de Belén Villena, disponible en:

http://www.estudiosaraucanos.cl/.

Diccionario etimológico de voces chilenas derivadas de lenguas indígenas americanas. Edición dirigida por M. Ferreccio Podestá. 1905-1910, Santiago, Universidad de Chile, 1979.

Lizana, Mectilde. Historia de la casa de la Providencia del Sagrado Corazón en Temuco. Santiago, Imprenta de la Revista Católica, 1904.

Malvestitti, Marisa. "Lingüística misionera en Pampa y Patagonia (1860-1930)". Revista Argentina de Historiografía Lingüística II, $\mathrm{N}^{\circ} 1,2010$, pp. 55-73.

"Dios ñi zugu. Los instrumentos de evangelización empleados en territorio mapuche (Siglos XVII-XX)". Actas del II Coloquio Internacional "Escrituras de la Traducción Hispánica”. Albert Freixa y Juan López (eds.), San Carlos de Bariloche, 2011, pp. 193-213.

"Nahuelpi: escritos en mapuzugun, presente y memoria del pueblo mapuche en la etapa posterior al awkan". Quinto Sol 23, N³, 2019.

Malvestitti, Marisa y María Andrea Nicoletti. "Evangelización franciscana en Araucanía: El catecismo de Serviliano Orbanel”. CORPUS 2, N², 2011.

Malvestitti, Marisa y Gertrudis PayÀs. "Circulaciones intertextuales del Arte de Febrés a ambos lados de los Andes". Araucanía-Norpatagonia III: Discursos y representaciones de la materialidad. María Nicoletti, Paula Núñez y Andrés Núñez (eds), Bariloche, Universidad Nacional de Río Negro, 2015, pp. 282-303.

Manquilef, Manuel. "Comentarios del pueblo araucano I: La faz social". Anales de la Universidad de Chile 128, $\mathrm{N}^{\circ} 1,1911$, pp. 393-450.

"Comentarios del pueblo araucano II, La jimnasia nacional (juegos, ejercicios i bailes)". Anales de la Universidad de Chile 134, N²72, 1914, pp. 239-301.

Mansilla, JuAn et al. "Instalación de la escuela monocultural en la Araucanía, 1883-1910: dispositivos de poder y Sociedad Mapuche”. Educação e Pesquisa 42, №1, 2016, pp. 213-228.

Matte, Claudio. Nuevo método (fonético, analítico-sintético) para la enseñanza simultánea de la lectura i escritura compuesto para las escuelas de la República de Chile. Leipzig, Imprenta de F. A. Brockhaus, 1894.

MENARD, ANDRÉ. “¿Qué fue primero, el archivo o el fetiche? En torno a los archivos indígenas”. Quinto Sol 23, N³, 2019.

Menard, André y Jorge Pavez. Mapuche y anglicanos. Vestigios fotográficos de la Misión Araucana de Kepe, 1895-1908. Santiago, Ocho Libros Editores, 2007.

Middendorf, ERnst. Die Aymará Sprache. Leipzig, F.A. Brockhaus, 1891.

Mora, Héctor y MARio SAMANiEgo (eds.). El pueblo mapuche en la pluma de los araucanistas. Seis estudios sobre construcción de la alteridad. Santiago, Ocho Libros Editores, 2018. 
Nicoletti, María y Marisa Malvestitti. "Catecismos en mapuzungun en el área cordillerana norpatagónica: práctica misionera y relaciones intertextuales”. 3as Jornadas de Historia de la Patagonia, 2008.

"Werkenealu Dios tañi zugun/ Para llevar el mensaje de Dios. Los catecismos en lengua indígena en el área territorial mapuche (s. XIX)”. Estudios Trasandinos 15, N 1 , 2009, pp. 5-27.

Noggler, Albert. Cuatrocientos años de misiones entre los araucanos. Padre las Casas, Imprenta y editorial San Francisco, 1982.

Pamplona, Ignacio. Historia de las Misiones de los Padres Capuchinos en Chile y Argentina (1849-1911). Santiago, Imprenta Chile, 1911.

Pavez, Jorge. "Las cartas del Wallmapu". Cartas mapuche: Siglo XIX. Jorge Pavez (comp.), Santiago, CoLibris \& Ocho Libros, 2008, pp. 9-114.

Pavez, Jorge, Gertrudis Payàs y Fernando Ulloa. "Los intérpretes mapuche y el Protectorado de Indígenas (1880-1930): constitución política de la propiedad, traducción y castellanización en Ngulumapu". Boletín de Filología 55, N¹, 2020, pp. 161-198.

Payàs, Gertrudis, José Manuel Zavala, Jorge Pavez y Darío Rojas. “Mediación lingüísticocultural y castellanización en los ámbitos de contacto mapudungun-castellano derivados del proceso de chilenización de la Araucanía (1880-1930)”. Proyecto Fondecyt Regular 1170419 (2017-2020).

Payàs, Gertrudis, José M. Ortiz y Aurora Sambolin. "Representación de la lengua mapuche en los usos de la traducción de Manuel Manquilef (Maquehue, Chile, 1887-1950)". Meta 66, $\mathrm{N}^{\circ} 02,2021$.

Poblete, Juan. Literatura chilena del Siglo XIX: Entre públicos lectores y figuras autoriales. Santiago, Editorial Cuarto Propio, 2002.

RoJAS, DARío. "Actitudes e ideologías de hispanohablantes en torno a las lenguas indígenas en el Chile del Siglo XIX”. Lenguas Modernas 42, 2013, pp. 85-98.

Röttingen, Bucardo. "25 años de actividad misional de los misioneros capuchinos bávaros en la misión araucana de Chile (1896-1921). Relación presentada por el P. Bucardo María de Roettingen al Prefecto Apostólico y Superior Regular". Traducido por Alfonso Tolosa del texto original alemán. Archivo Obispado de Villarrica. Ms. mecanografiado, 1922.

SÁnCHEZ, Gilberto. "Los quechuismos en el mapuche (mapudungu(n)), antiguo y moderno". Boletín de Filología 55, $\mathrm{N}^{\circ} 1,2020$, pp. 355-377.

Sebba, Mark. Spelling and Society. The Culture and Politics of Orthography Around the World. Cambridge, Cambridge University Press, 2007.

Serrano, Sol. "De escuelas indígenas sin pueblos a pueblos sin escuelas indígenas: la educación en la Araucanía en el Siglo XIX”. Revista de Historia 29, 1996, pp. 423-474.

Serrano, Sol, Macarena Ponce y Francisca Rengifo. Historia de la educación en Chile (1810-2010). Tomo I. Aprender a leer y escribir (1810-1880). Santiago, Taurus, 2012.

Historia de la educación en Chile (1810-2010). Tomo II. La educación nacional (1880-1930). Santiago, Taurus, 2012.

Torre Revello, José. "Las cartillas para enseñar a leer a los niños en América española". Boletín del Instituto Caro y Cuervo 15, N¹-3, 1960, pp. 214-234. 
Vezub, Julio e Ingrid De Jong. "El giro escritural en la historiografía mapuche: alfabeto y archivos en las fronteras. Un estado de la cuestión”. Quinto Sol 23, N³, 2019.

VIVAR, JULIETA. "El lugar del indígena en la política mexicana de alfabetización. Un análisis crítico de las Cartillas de Alfabetización para Indígenas Monolingües (1944-1949)”. Tesis para optar al grado de Magíster en Estudios Latinoamericanos, Santiago, Universidad de Chile, 2012. 


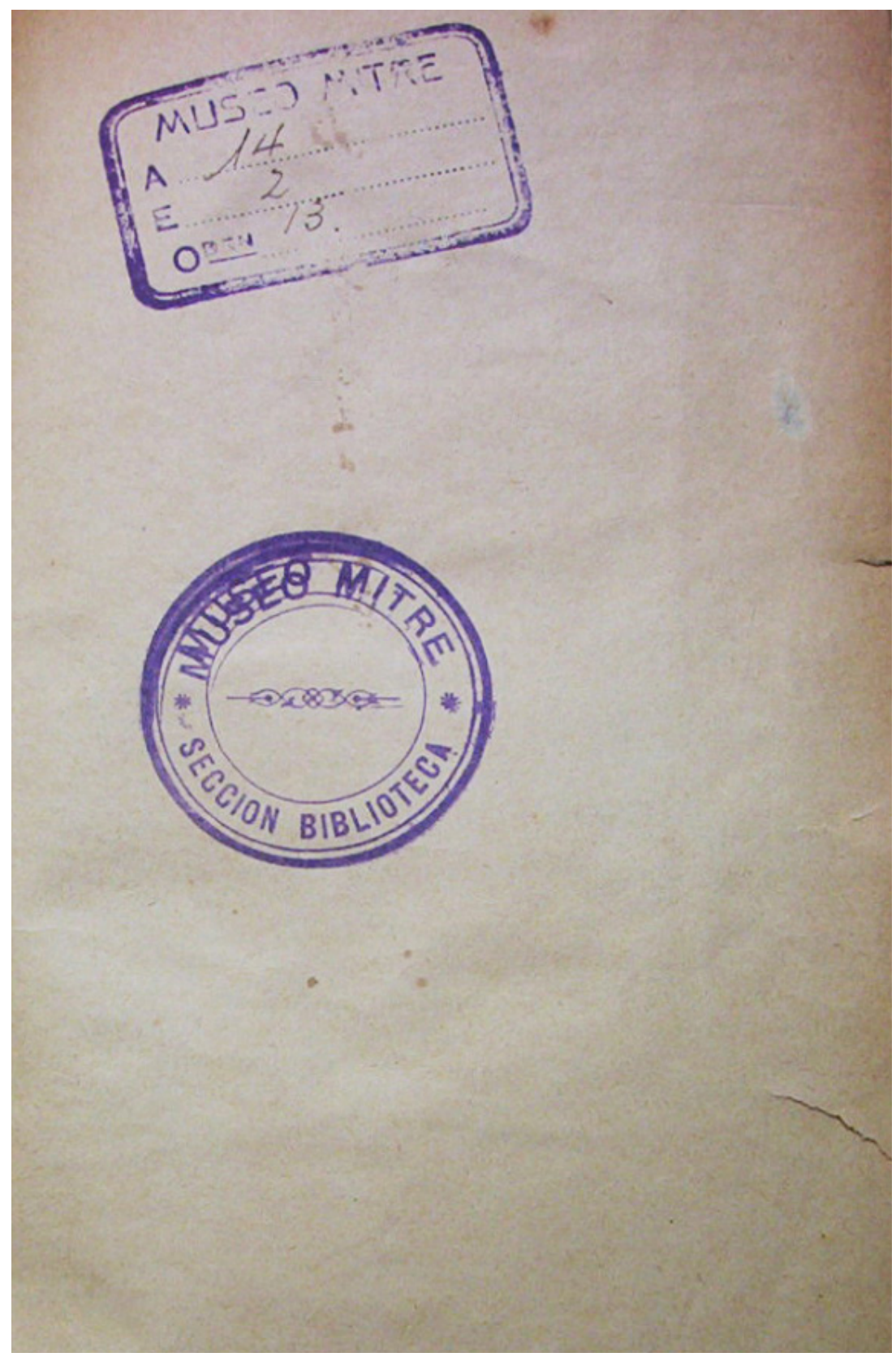


130

Revista Chilena de Literatura No 104, 2021

Chilcaton thice rugnes<smiles>C1=CCCCC1</smiles> 


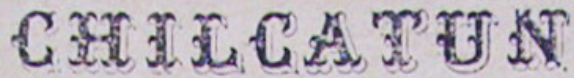

\section{CIIILE DUGNU}

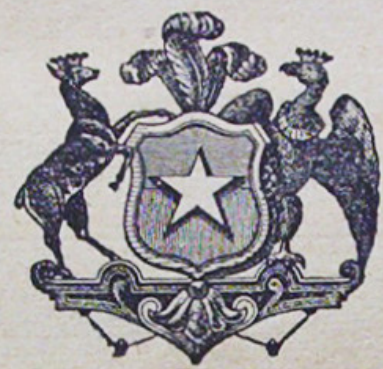

SANTIAGO DE CHILE.

IMPRENTA DE SAN JOSÉ

C'asa Central de la Providencia.

1899 

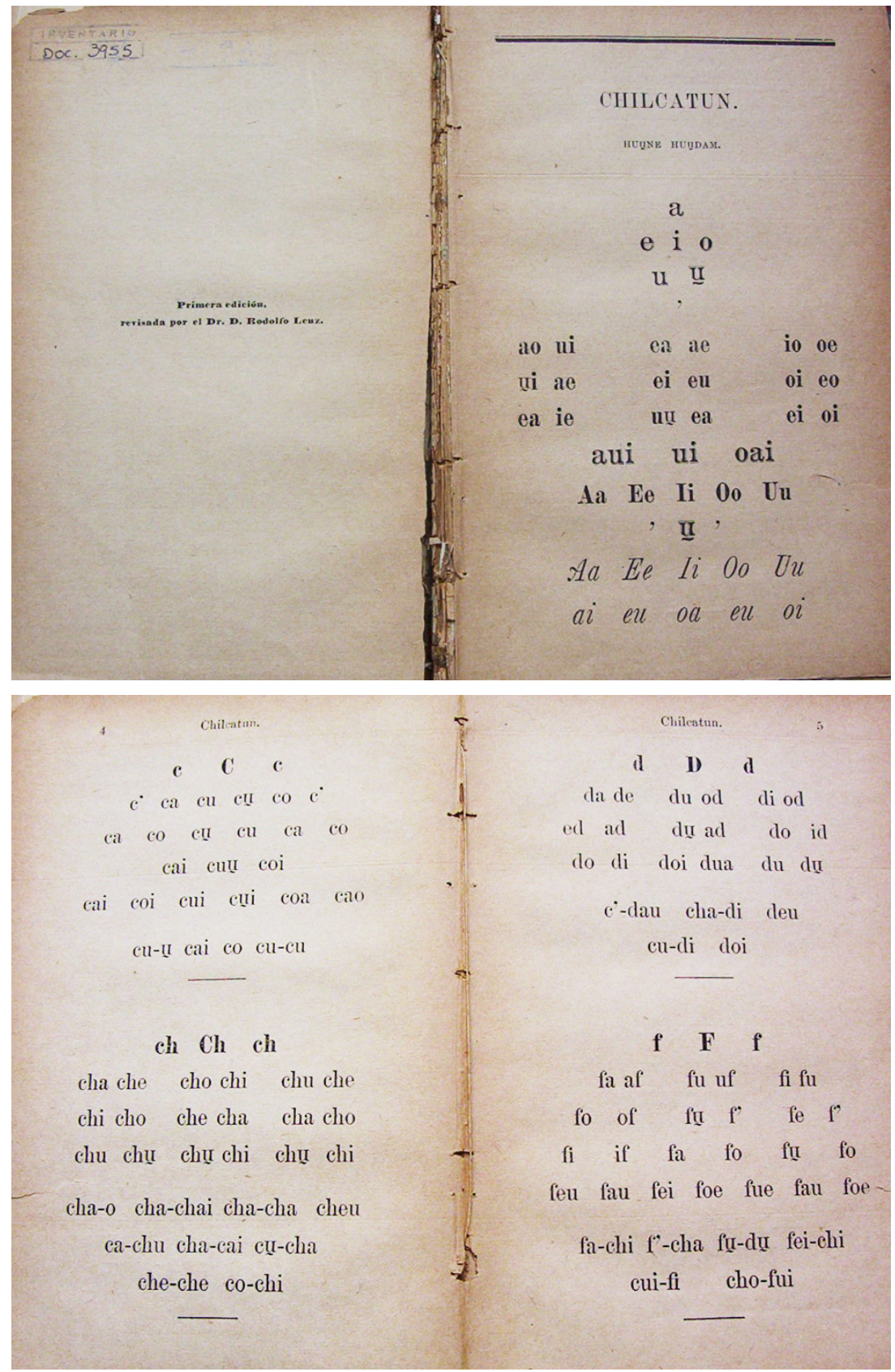

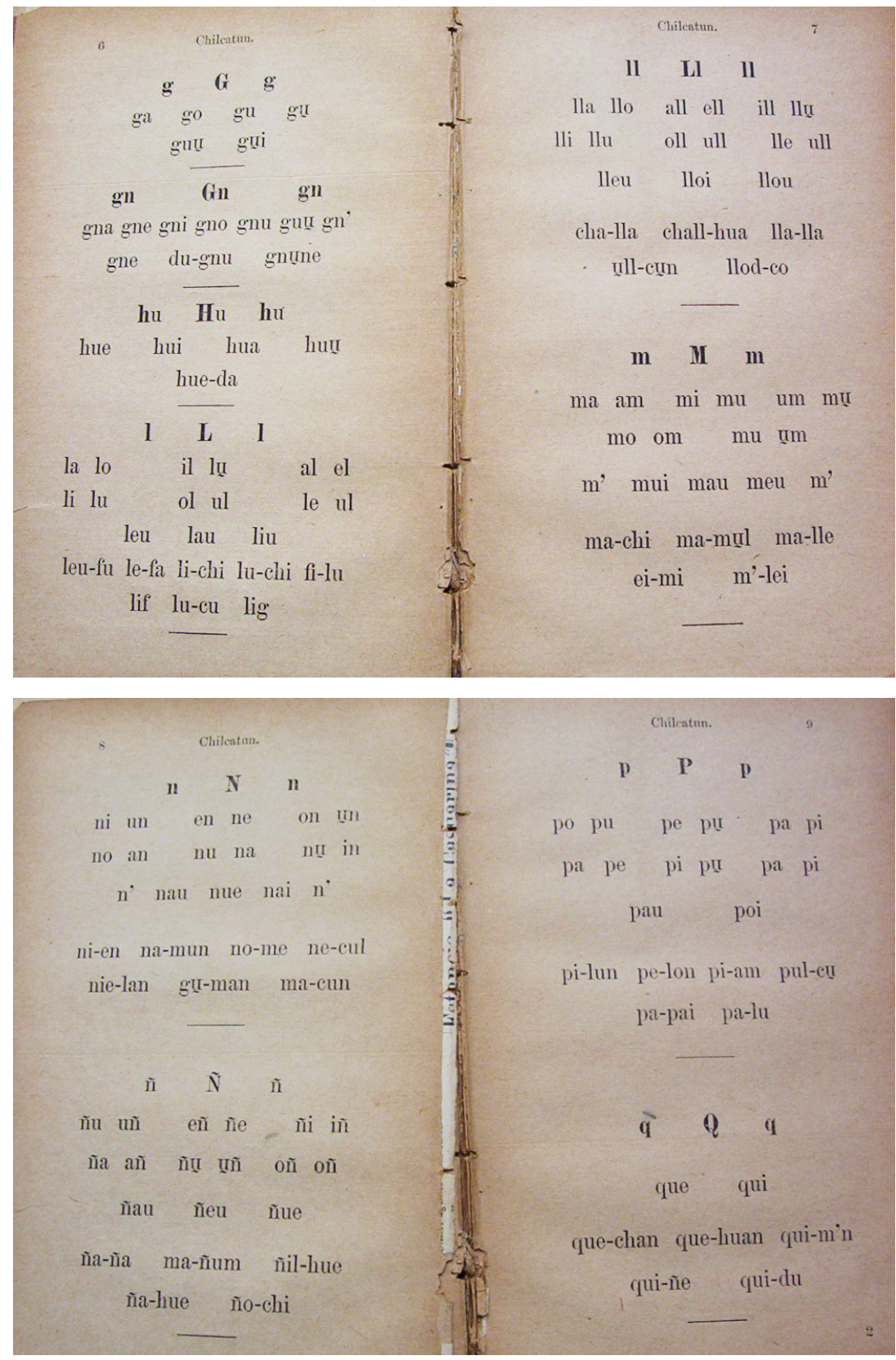


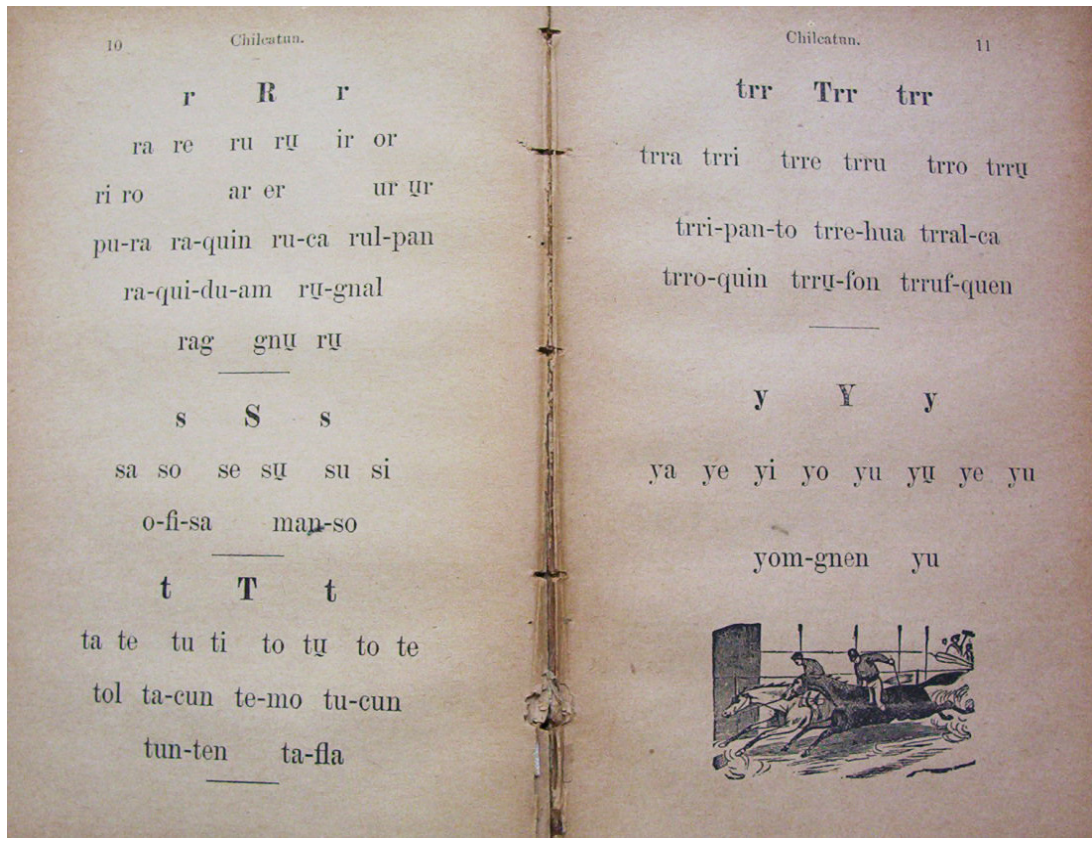

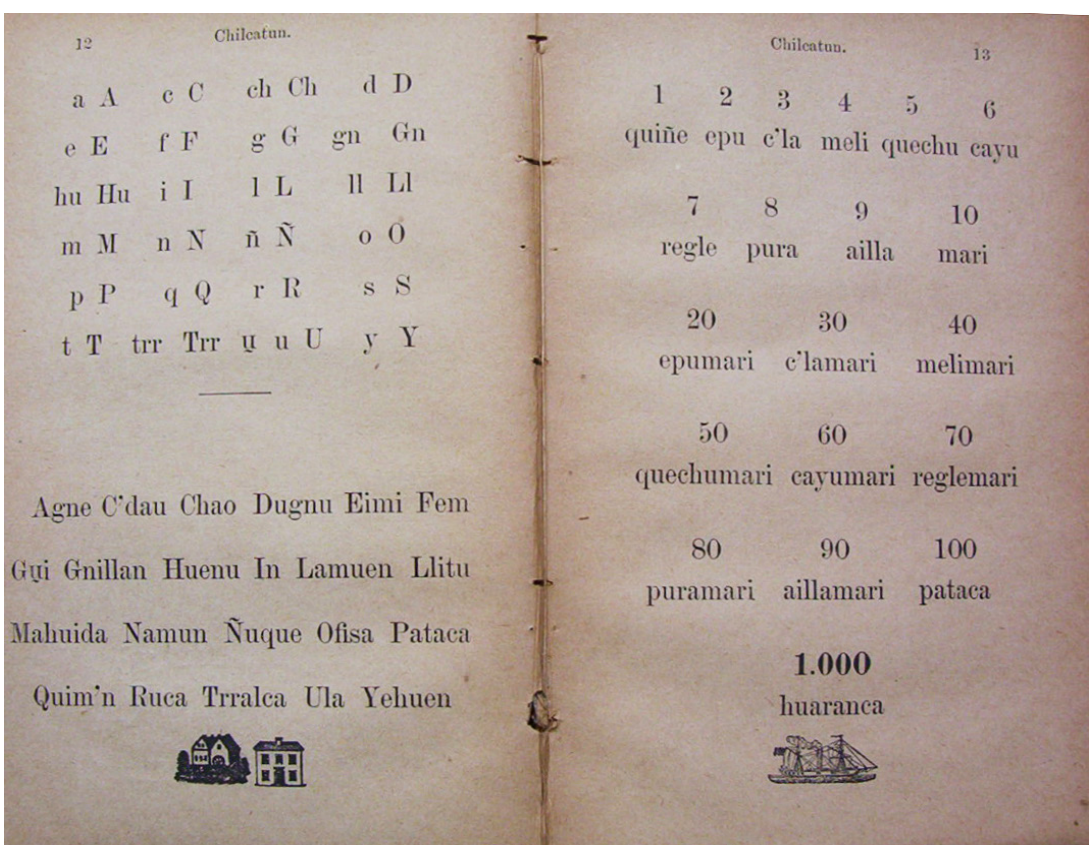



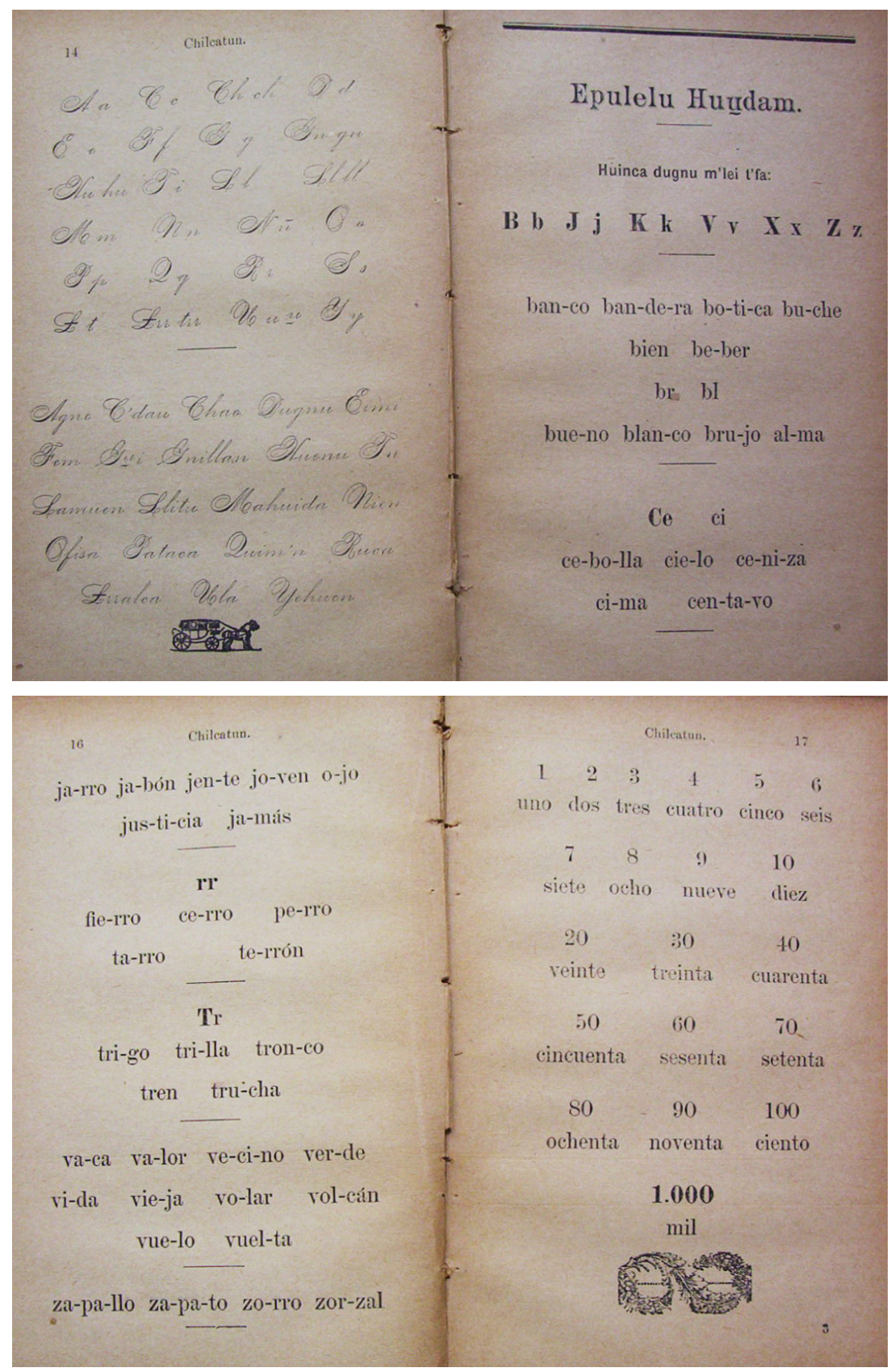

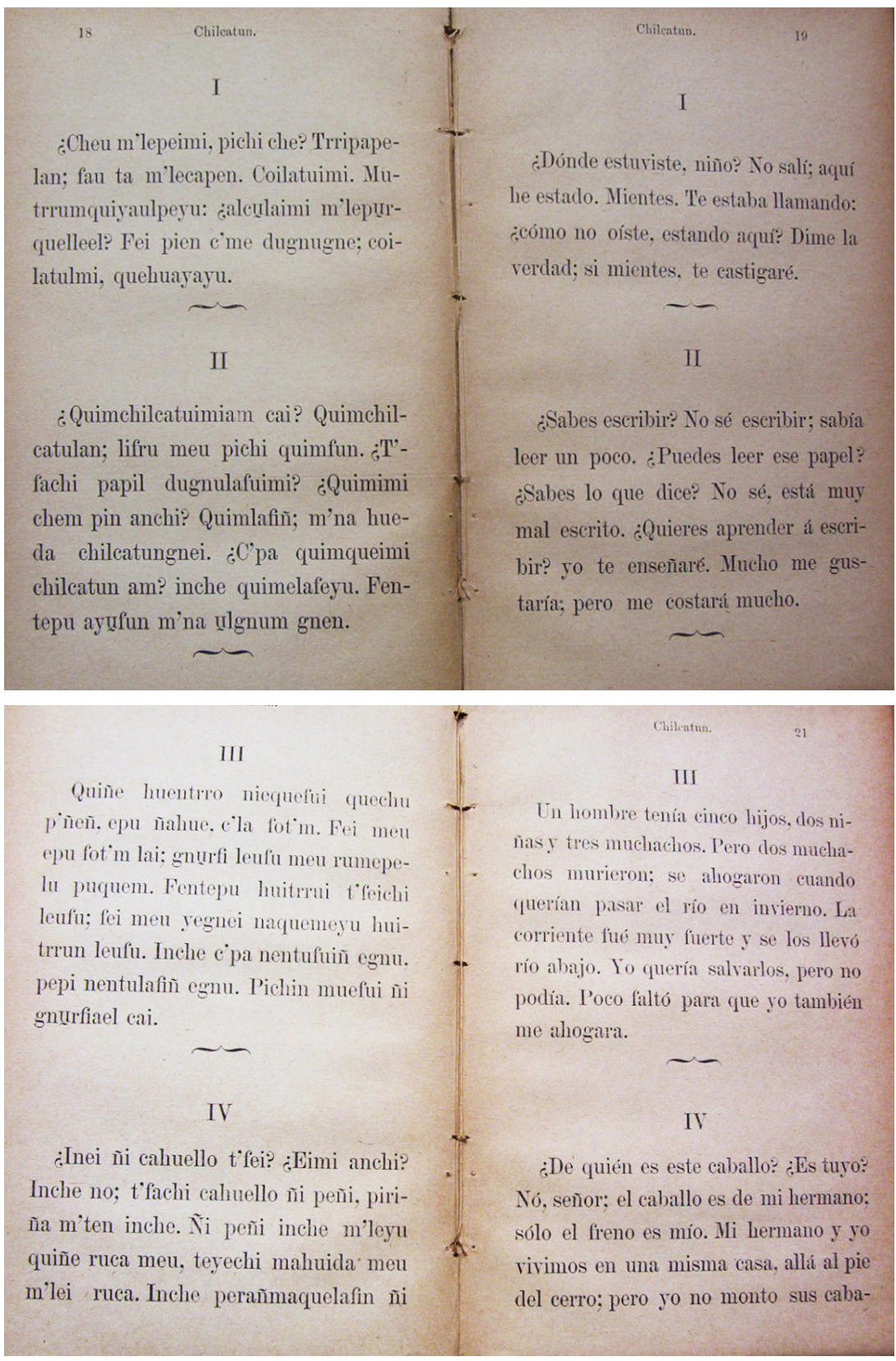


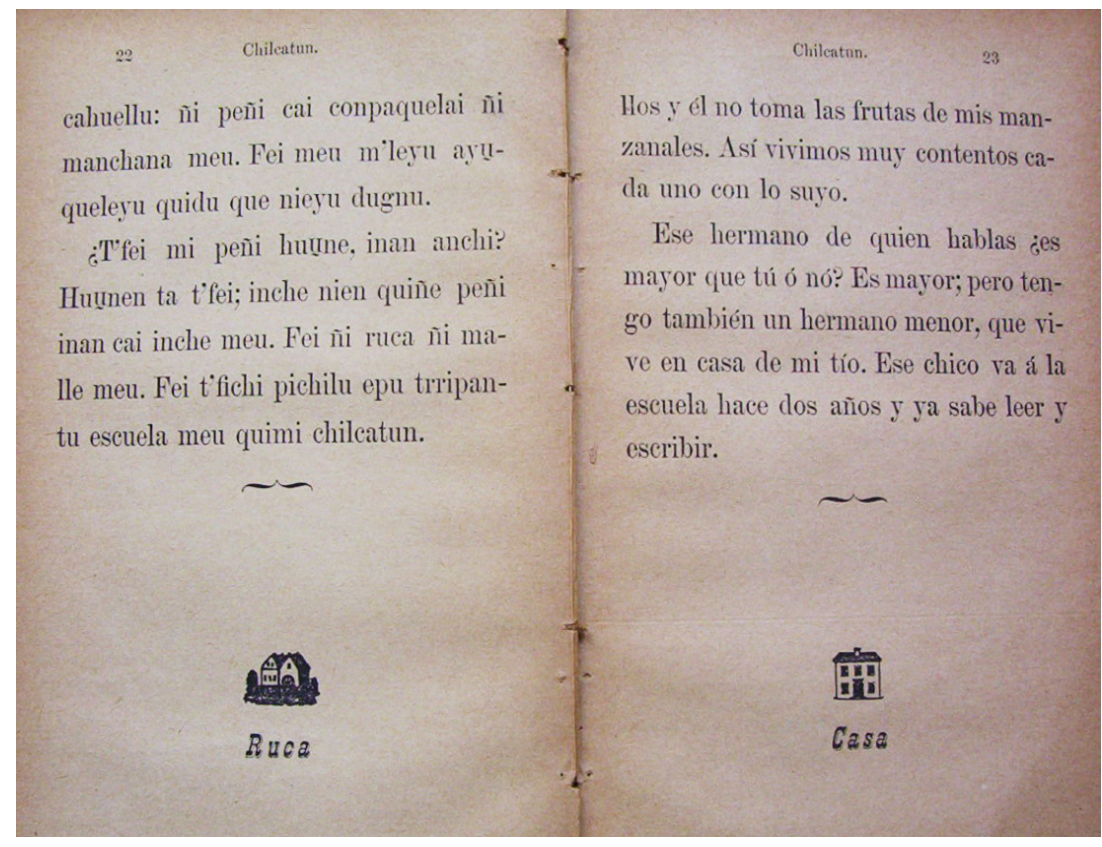

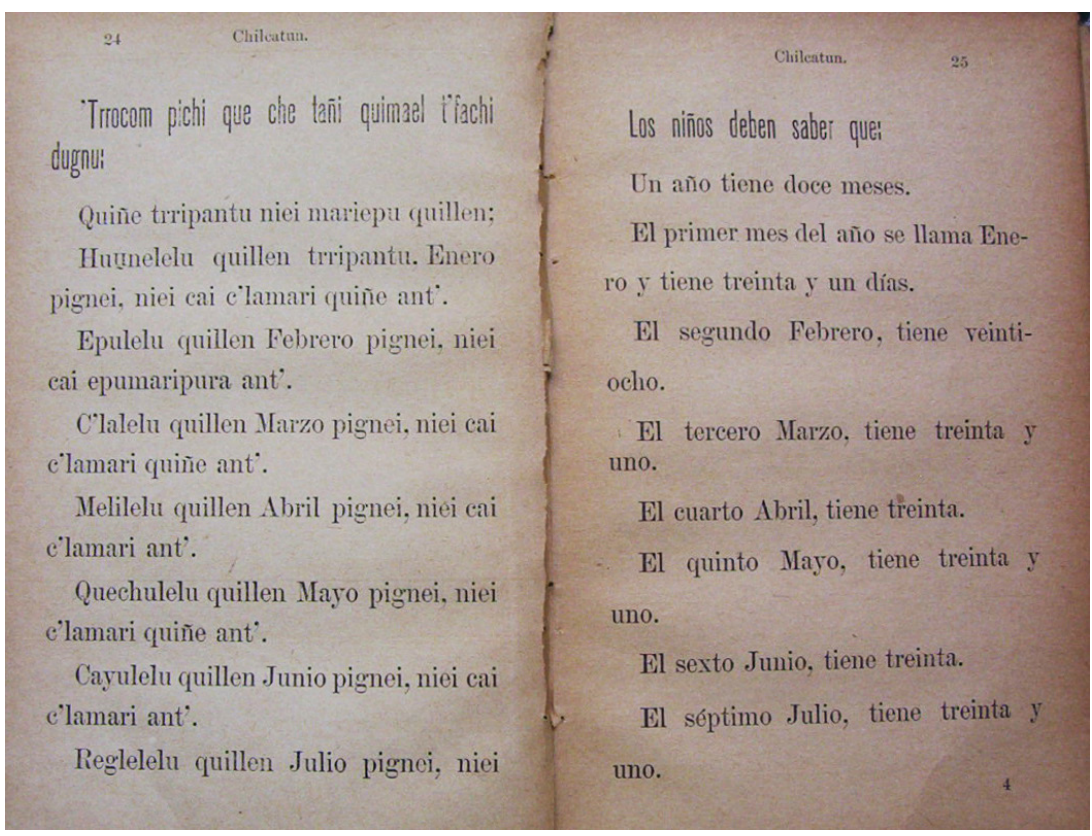




\begin{tabular}{|c|c|}
\hline $\begin{array}{l}\text { Puralelu quillen Agosto pignei, niei } \\
\text { cai c'lamari quiñe ant'. } \\
\text { Aiyalelu quillen Setiembre pignei, } \\
\text { niei cai c'lamari ant'. } \\
\text { Marilelu quillen Octubre pignei, niei } \\
\text { cai c'lamari quiñe ant'. } \\
\text { Mariquiñe quillen Noviembre pignei, } \\
\text { niei cai c'lamari ant'. } \\
\text { Mariepu quillen Diciembre pignei, } \\
\text { niei cai c'lamari quiñe ant'. } \\
\text { Pataca trripantu trrauclei siglo pi- } \\
\text { gnei. } \\
\text { Quiñe trripantu niei cafei meli esta- } \\
\text { cion pigneign'n: peuggnen, hualøgn, } \\
\text { hualugn puquem cai. } \\
\text { Quiñe quillen niei meli semana. } \\
\text { Regle ant' trrauclei, semana pignei. }\end{array}$ & $\begin{array}{l}\text { El octavo Agosto, tiene treinta y } \\
\text { uno. } \\
\text { El noveno Setiembre, tiene treinta. } \\
\text { El décimo Octubre, tiene treinta y } \\
\text { El undécimo Noviembre, tiene trein- } \\
\text { ta. } \\
\text { El duodécimo Diciembre, tiene trein- } \\
\text { ta y uno. } \\
\text { Un siglo tiene cien años. } \\
\text { Un año se divide también en cuatro } \\
\text { estaciones: } \\
\text { Primavera, Verano, Otoño é Invierno. } \\
\text { Un mes tiene cuatro semanas y la } \\
\text { semana siete días. }\end{array}$ \\
\hline
\end{tabular}

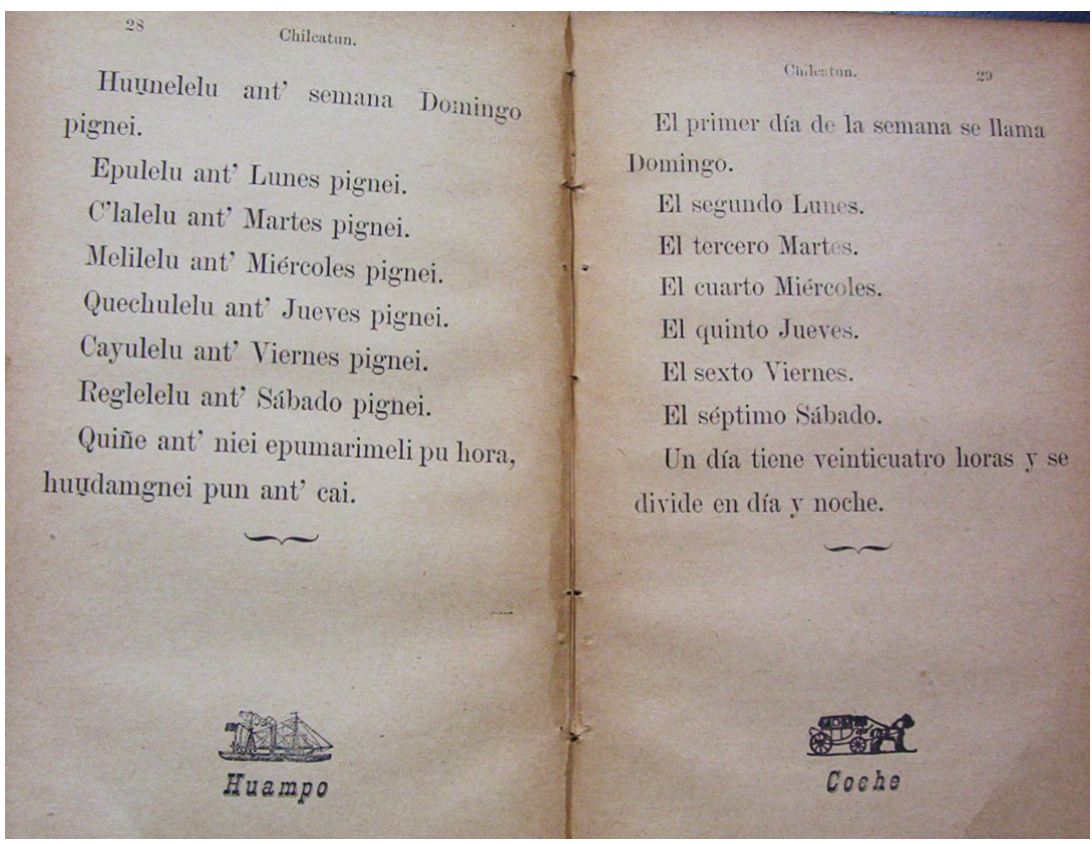




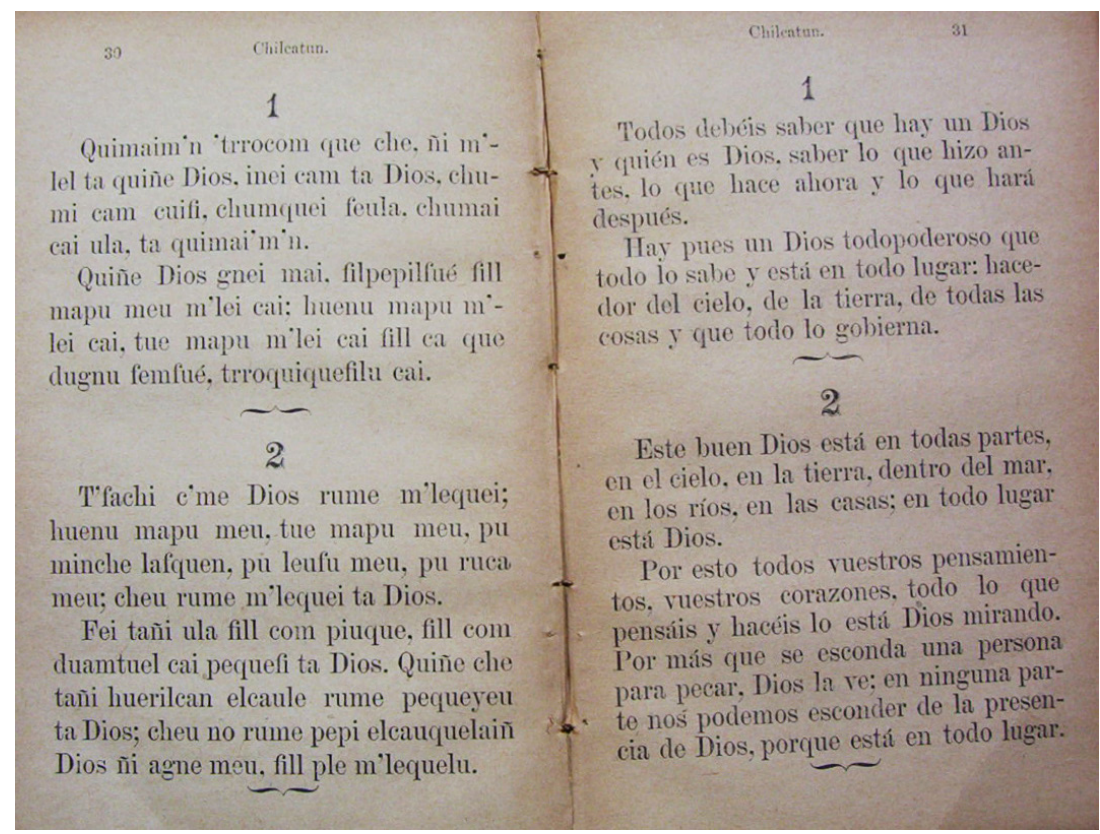

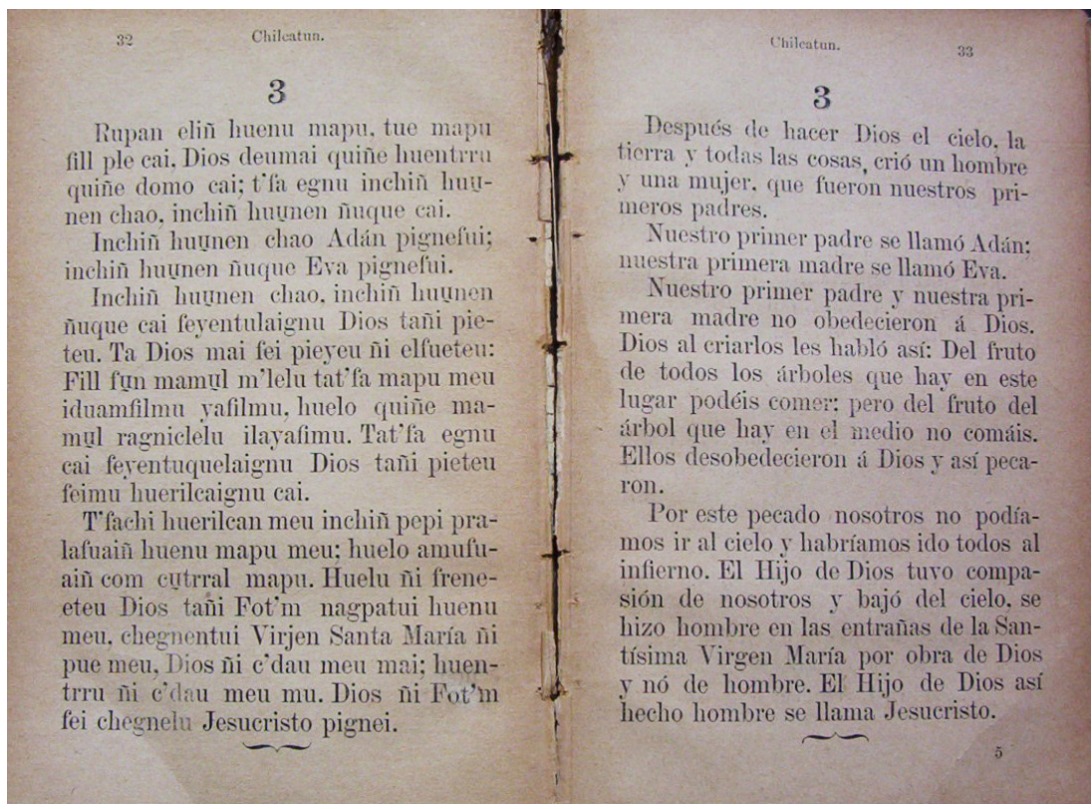



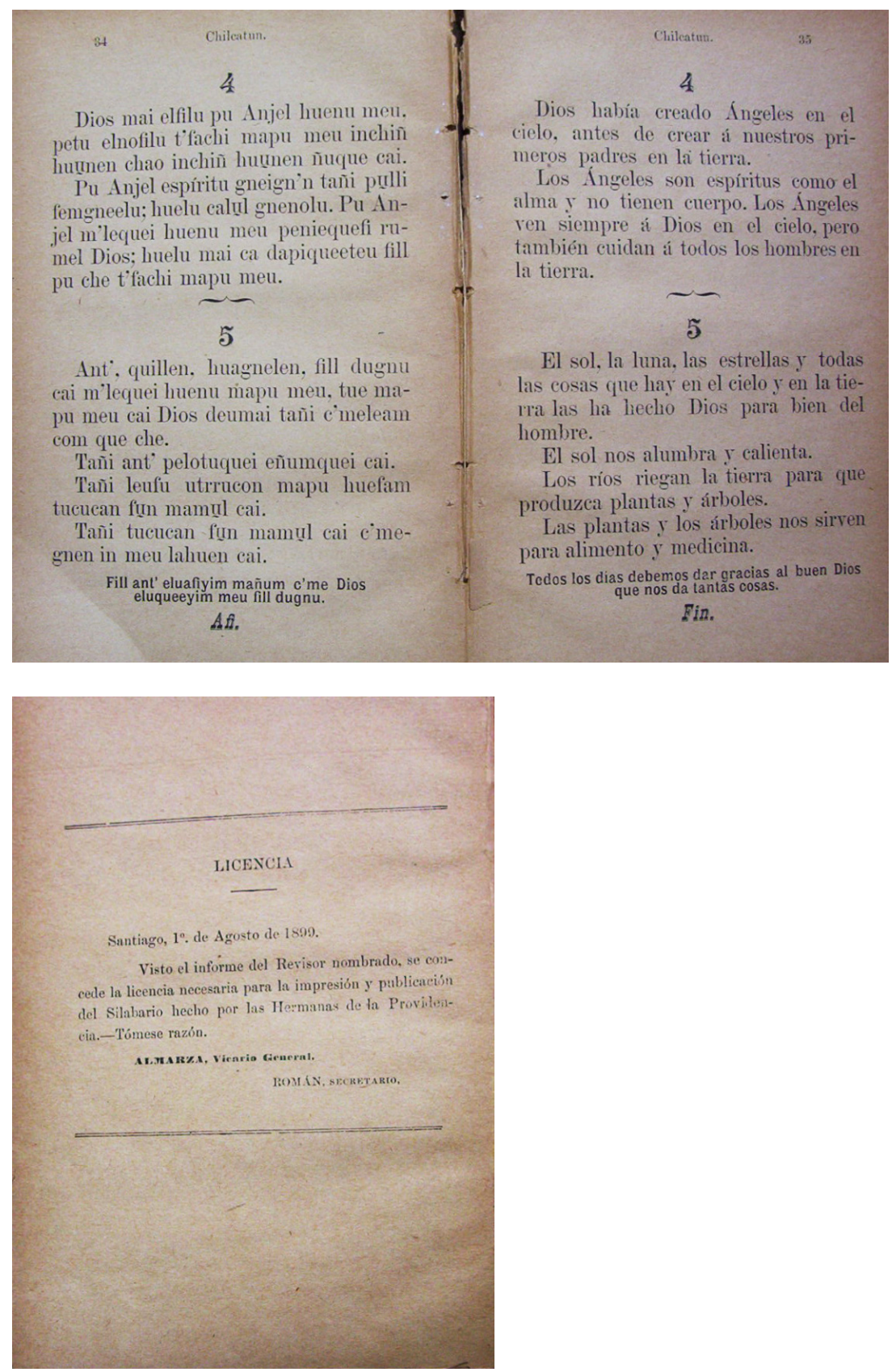

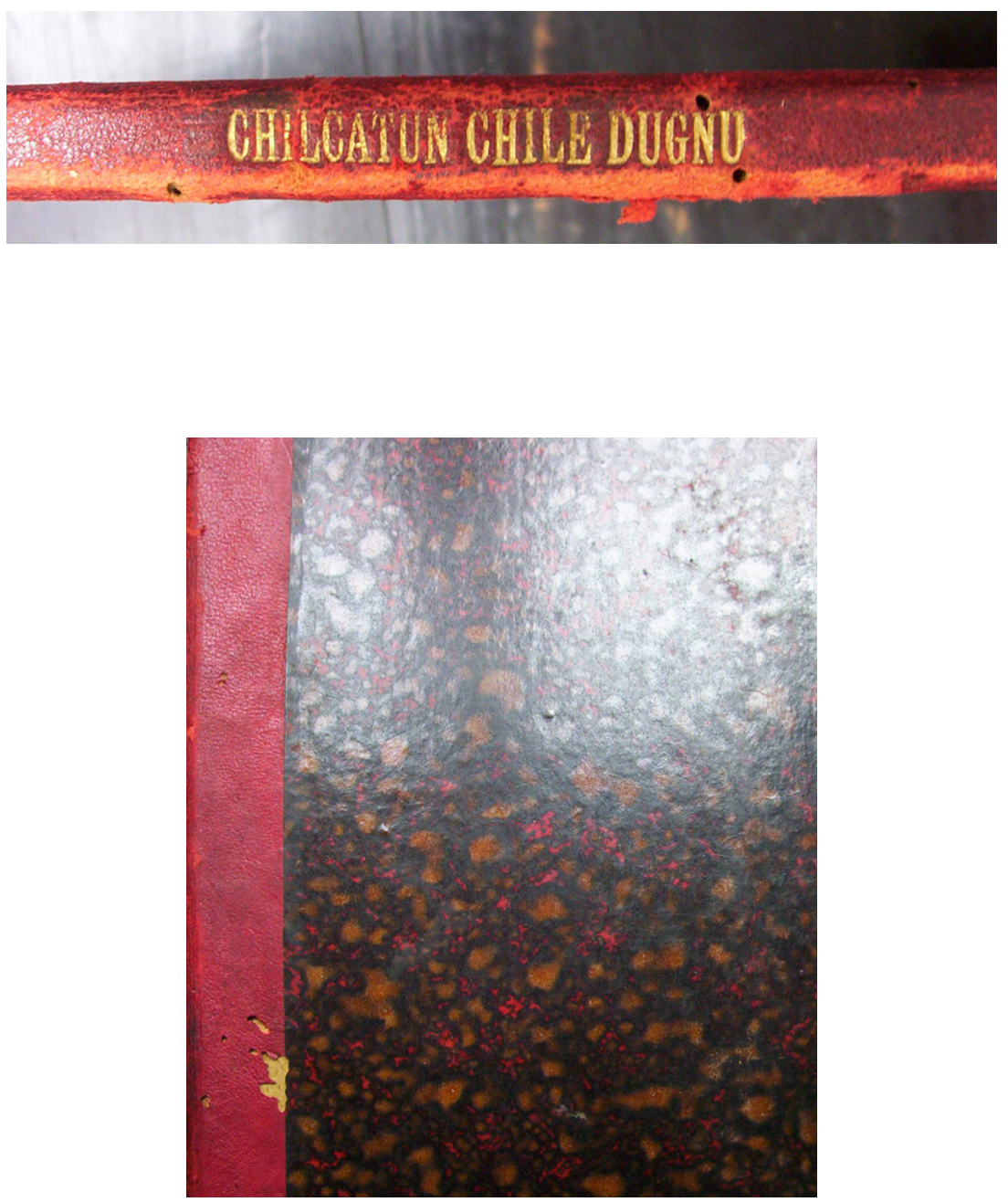
